\title{
Formação de professores de Química em 26 anos de publicações na revista Química
}

\section{Nova na Escola}

\author{
Chemistry teachers' education in 26 years of publications in the Química Nova na Escola journal \\ Formación de profesores de Química en 26 años de publicaciones en la revista Química Nova na \\ Escola
}

Recebido: 13/08/2021 | Revisado: 22/08/2021 | Aceito: 28/08/2021 | Publicado: 29/08/2021

\author{
Any Caroline Ferreira \\ ORCID: https://orcid.org/0000-0002-1476-6336 \\ Universidade Estadual de Londrina, Brasil \\ E-mail: any.c.ferreira@uel.br \\ Marinez Meneghello Passos \\ ORCID: https://orcid.org/0000-0001-8856-5521 \\ Universidade Estadual de Londrina, Brasil \\ E-mail: marinezpassos@uel.br \\ Sergio de Mello Arruda \\ ORCID: https://orcid.org/0000-0002-4149-2182 \\ Universidade Estadual de Londrina, Brasil \\ E-mail: sergioarruda@uel.br \\ Rosana Figueiredo Salvi \\ ORCID: https://orcid.org/0000-0001-9475-9867 \\ Universidade Estadual de Londrina, Brasil \\ E-mail:salvi@uel.br
}

\begin{abstract}
Resumo
Esta pesquisa teve por objetivo investigar, nos artigos publicados na revista Química Nova na Escola (QNESC), como a temática formação de professores de Química foi compreendida pelos pesquisadores da área no período de 19952020. A metodologia para coleta e análise dos dados foi inspirada na Análise Textual Discursiva. Os resultados mostraram que a maioria dos artigos sobre formação de professores de Química foi publicada nos últimos doze anos do período. A partir dos dados foi possível destacar algumas tendências a respeito do que tem sido divulgado na QNESC referente ao tema em questão. Entre eles relacionamos: Formação inicial; Formação continuada; Profissionalização docente; Prática pedagógica; as quais já haviam sido identificadas em pesquisas anteriores. No entanto, dos dados também emergiram duas novas categorias denominadas por Artigos que mesclam categorias e Outras temáticas e a formação de professores. Observou-se também uma carência de artigos referentes à Formação continuada, sendo essa uma lacuna a ser investigada.
\end{abstract}

Palavras-chave: Formação de professores; Ensino de química; QNESC.

\begin{abstract}
This research had for objective inquire in the articles published in the journal Química Nova na Escola (QNESC), how the theme of Chemistry teachers' education was understood by researchers in the period 1995-2020. The results showed that the majority of articles on this field were published in the last twelve years of the period. The methodology for data collection and analysis was inspired by Discursive Textual Analysis. From the data, it was possible to highlight some trends regarding what has been disclosed in QNESC regarding the topic in question. Among them we list: Initial training; Continuing education; Teacher professionalization; Pedagogical practice; which had already been identified in previous research. However, two new categories emerged from the data, called Articles that mix categories and Other themes and teacher education. There was also a lack of articles referring to Continuing Education, which is a gap to be investigated.
\end{abstract}

Keywords: Teacher education; Chemistry teaching; QNESC.

\section{Resumen}

Esta investigación tuvo como objetivo indagar, en los artículos publicados en la revista Química Nova na Escola (QNESC), cómo la temática de la formación del profesorado de química fue entendida por los investigadores del campo en el período 1995-2020. La metodología para la recopilación y el análisis de datos se inspiró en el análisis textual discursivo. Los resultados mostraron que la mayoría de los artículos sobre la formación del profesorado de química se publicaron en los últimos doce años del período. A partir de los datos, fue posible resaltar algunas tendencias con respecto a lo divulgado en QNESC con respecto al tema en cuestión. Entre ellos enumeramos: Formación inicial; Educación continua; Profesionalización docente; Práctica pedagógica; que ya había sido 
identificada en investigaciones anteriores. Sin embargo, de los datos surgieron dos nuevas categorías, llamadas Artículos que mezclan categorías y Otros temas y formación del profesorado. También faltaron artículos relacionados con la Educación Continuada, que es una laguna a investigar.

Palabras clave: Formación de profesores; Enseñanza de la química; QNESC.

\section{Introdução}

A formação de professores de Química, na última década, é um dos temas mais investigado por pesquisadores da área de Ensino de Química. Em breve revisão da literatura, encontramos alguns estudos que se dedicaram ao tema.

Em Silva e Queiroz (2016), os autores fazem um levantamento bibliográfico de dissertações e teses, no período de 2001 a 2010, que abordava a formação de professores de Química, com o intuito de identificar quais as tendências dessa linha de pesquisa no Brasil. Os resultados "indicaram a consolidação da área de pesquisa em formação de professores de Química no país, mostrando um aumento da produção no período analisado" (Silva \& Queiroz, 2016, p.62).

Em outro artigo (Silva \& Queiroz, 2017), os autores classificaram as dissertações e teses em cinco focos temáticos: "formação inicial", que englobou estudos a respeito da formação inicial de professores, incluindo questões referentes à licenciatura; "formação continuada", em que incluíram trabalhos relacionados à investigação de programas e cursos de formação continuada; "identidade e profissionalização docente", destacam-se as investigações relacionadas ao professor, sua ação, concepções e saberes; no foco "prática pedagógica", os autores acomodaram dissertações e teses que pesquisaram a prática docente realizada em sala de aula; no último foco, denominado por "outros", incluíram aquilo que não se enquadrava nos quatro primeiros.

Temos ainda a publicação de Silva e Santos (2015), em que consideraram artigos pertencentes à Revista Química Nova na Escola (QNESC), no período de 2004 a 2014, e investigaram os artigos que abordaram a formação de professores de Química, com a finalidade de obter melhor conhecimento e compreensão dessa área. Encontraram 33 artigos que tratavam da formação de professores, os quais foram classificados de acordo com o assunto em foco: Programa Institucional de Bolsa de Iniciação à Docência - PIBID, experimentação, currículo, licenciaturas, dentre outros.

Devido à importância da área de formação de professores de Química, apontada por Maldaner (2013), e dos diversos aspectos a serem considerados para essa formação, como comentado por Lôbo e Moradillo (2003); Maldaner (1999); Schnetzler (2002); Silva, Alves Junior, Travassos e Carmo (2008), buscou-se ampliar as pesquisas de Silva e Santos (2015); Silva e Queiroz (2016, 2017), com o intuito de avançar e ampliar essas compreensões já expostas.

Ao considerar o tema desta investigação - Formação de professores de Química - foi levantada a seguinte questão de pesquisa: $\mathrm{O}$ que pesquisadores da área têm publicado acerca do tema formação de professores de Química no periódico QNESC no período de 1995 a 2020 ?

Com o propósito de entender quais aspectos são importantes para a formação de professores de Química foram estudados diversos referenciais, os quais discutem a respeito da formação de professores de Ciências, das necessidades formativas para os professores de Ciências e da formação de professores de Química. Alguns destaques relativos a esse movimento nós abordamos na seção a seguir, procurando elucidar o olhar que tivemos durante a investigação.

\subsection{Referenciais teóricos}

Diante da importância do conhecimento científico e tecnológico para a sociedade, o Ensino de Ciências precisa buscar construir conhecimentos que auxiliem na formação de cidadãos críticos, sendo o professor o responsável por mediar a construção desse conhecimento.

Dentro desse contexto, os cursos de formação de professores de Ciências devem possibilitar ao docente: compreender os conhecimentos científicos e a influência destes nos aspectos da Ciência, social e cultural; conhecimentos de estratégias de 
ensino e de aprendizagem; refletir a respeito de suas próprias práticas educativas (Nascimento, Fernandes \& Mendonça, 2010). Além disso, essa formação precisa trabalhar os estudos teóricos em conjunto com as atividades práticas e desenvolver pesquisas (Silva \& Bastos, 2012). Dessa forma, a formação de professores pode oferecer aos futuros docentes conhecimentos específicos da Ciência e também contribuir para uma formação política, estética e ética no processo de ensino e aprendizagem (Santos, Sousa \& Derossi, 2020).

No campo da formação de professores de Ciências, podem ser pesquisados assuntos relacionados à formação inicial e continuada. Na formação inicial de professores, os aspectos a serem investigados estão relacionados com os cursos de licenciatura (Galiazzi \& Moraes, 2002). Existem diversas adversidades nesses cursos, como a desarticulação entre a formação acadêmica e a realidade escolar e o distanciamento entre disciplinas de conteúdo específicos e pedagógicas (Galiazzi \& Moraes, 2002; Nascimento et al., 2010; Zimmermann \& Bertani, 2003). Com o intuito de solucionar esses problemas, são realizadas discussões a respeito das problemáticas existentes nas licenciaturas e propostas de reformulação de alguns cursos (Nascimento et al., 2010).

É importante minimizar o distanciamento das disciplinas para que os futuros professores consigam integrar os conteúdos científicos às questões pedagógicas. Logo, é necessária uma formação que trabalhe o conhecimento em conjunto com a ação; na atividade docente é importante que o professor reflita a respeito das situações presentes no seu ambiente de ensino. A formação inicial precisa auxiliar o licenciando a compreender a sala de aula, mas é por meio da reflexão que ele vai conseguir entender as necessidades dos alunos e então buscar melhorar o desenvolvimento do seu trabalho (Zimmermann \& Bertani, 2003).

Outro aspecto a ser considerado na formação inicial de professores são as práticas pedagógicas. Considera-se que utilizar práticas que incentivem o estudante a participar de forma ativa na construção do seu conhecimento tem sido eficiente para que este se aproprie melhor dos conteúdos necessários para sua formação. No entanto, o trabalho do professor não está voltado exclusivamente para o ato de ensinar, sendo necessário que o docente participe também da elaboração de currículos e de outras questões relacionadas à escola. Logo, é preciso que na formação inicial sejam trabalhados assuntos referentes à docência, à gestão educacional e à produção de conhecimentos da Educação (Silva \& Bastos, 2012).

Esses aspectos comentados anteriormente estão relacionados com a formação inicial, contudo é fundamental que o professor aprimore seus conhecimentos, por meio da formação continuada, para desenvolver novas práticas em sala de aula (Zimmermann \& Bertani, 2003). Por isso, é necessário que na formação continuada de professores de Ciências sejam considerados os conhecimentos científicos e os aspectos relacionados às questões educacionais, pois não é possível desvincular o Ensino de Ciências do âmbito educacional (Selles, 2002).

É importante também que o professor desenvolva o conhecimento didático, para que o mesmo saiba como ensinar. Uma boa forma de desenvolver essa aprendizagem é incluir na formação continuada sequências didáticas, para que o professor tenha contato com os conceitos científicos e com as metodologias que vai utilizar para trabalhar com os estudantes.

Considera-se essencial amplificar uma política de formação continuada, com leis que visem a necessidade de o desenvolvimento profissional docente acontecer de maneira institucionalizada. A criação da Rede Nacional de Formação Continuada de Profissionais da Educação Básica e a implantação do Plano Nacional de Formação de Professores da Educação Básica são alguns exemplos de mecanismos legais que já foram criados e são importantes para que os professores desenvolvam a formação continuada (Silva \& Bastos, 2012).

Com os diversos aspectos descritos a respeito do tema formação de professores de Ciências, considera-se que, para formar docentes de Ciências, é necessário ir além do conhecimento do conteúdo, o que nos remete às necessidades formativas que precisam ser consideradas na formação desses professores. 
Sabe-se que o Ensino de Ciências engloba muitos fatores e a atividade docente desenvolvida pelos professores de Ciências é complexa, logo eles precisam ter e adquirir um conjunto de conhecimentos. Sendo assim, Gil-Pérez e Carvalho (2003) apontam e discutem algumas necessidades formativas a serem desenvolvidas nos cursos de formação inicial e continuada. Destacaremos algumas delas nos próximos parágrafos.

A ruptura com visões simplistas sobre o ensino de Ciências - considera-se que desenvolver a formação de professores com base nas orientações construtivistas, é uma forma de romper com as visões simplistas que os professores de Ciências apresentam a respeito do Ensino de Ciências. Conhecer a matéria a ser ensinada - é fundamental que os professores entendam os conhecimentos científicos e sua relação com questões históricas, epistemológicas, sociais e tecnológicas.

É necessário, também, questionar as ideias docentes de "senso comum" sobre o ensino e aprendizagem das Ciências. Outra necessidade formativa é adquirir conhecimentos teóricos sobre a aprendizagem das Ciências -, por isso é preciso incluir a fundamentação teórica na formação dos professores e trabalhá-la em conjunto com os conhecimentos específicos. Saber analisar criticamente o "ensino tradicional" - é considerado como um saber essencial para o processo formativo.

Outro saber relevante é preparar atividades capazes de gerar uma aprendizagem efetiva - neste caso, é necessário saber elaborar atividades que incluam diversas estratégias. Saber dirigir o trabalho dos alunos e saber avaliar - também são consideradas como necessidades formativas. Além disso, para que os professores consigam analisar criticamente sua atividade docente, é fundamental adquirir a formação necessária para associar ensino e pesquisa didática (Gil-Pérez \& Carvalho, 2003).

Como pode ser verificado, nesta seção já destacamos algumas compreensões que assumimos para o desenvolvimento desta pesquisa quanto à formação de professores de Ciências. Apesar de a formação de professores de Química estar inclusa neste tema, optou-se por trazer também posicionamentos nossos pautados em teóricos da formação de professores de Química, pelo fato de este ser nosso assunto principal.

Há décadas é indicado que a formação de professores depende de muitos aspectos, uma vez que a docência vai além do conhecimento do conteúdo, sendo necessário que o educador conheça e se aproprie de uma metodologia de ensino. Além disso, na formação de professores é imprescindível abordar a respeito da relação professor-aluno e os instrumentos de avaliação (Lôbo \& Moradillo, 2003).

Durante a formação inicial, nos cursos de licenciatura, existem disciplinas de Práticas de Ensino de Química e Estágio Supervisionado, destinadas a trabalharem os conhecimentos essenciais da formação do professor de Química mencionados no parágrafo anterior. Essas disciplinas precisam ser desenvolvidas de forma integrada, com o intuito de conciliar teoria e prática, para possibilitar aos licenciandos a aprendizagem relacionada à atuação docente.

A realização do estágio possibilita ao licenciando, o contato com o futuro ambiente de trabalho e com situações que podem surgir no âmbito da atividade docente, favorecendo a confiança em relação ao comportamento que eles vão precisar apresentar futuramente em sua profissão (Kasseboehmer \& Ferreira, 2008).

Além das disciplinas pedagógicas e da carga horária destinada à prática como componente curricular e ao estágio supervisionado, percebe-se a importância de os licenciandos em Química participarem de projetos de iniciação científica, de iniciação à docência, de extensão e de monitoria, pois possibilitam ao futuro professor iniciar pesquisas científicas na área de Ensino de Química e espaços dentro da escola, para que este desenvolva atividades práticas (Conselho Nacional de Educação, 2015).

Contudo, essas ações não são fundamentais somente para a formação inicial, mas também para a continuada, por isso tais propostas precisam ser acompanhadas por meio de pesquisas, as quais devem ser desenvolvidas em conjunto com a escola. É fundamental que esse processo seja realizado em parceria com professores universitários, professores do Ensino Médio e alunos da graduação (Maldaner, 1999). Esse trabalho pode se tornar um processo de formação continuada, pois a reflexão a 
respeito das situações práticas da sala de aula é uma forma de encontrar os problemas de ensino e aprendizagem, e com isso buscar desenvolver novas práticas pedagógicas (Maldaner, 2013).

No que diz respeito à formação continuada, no estado do Paraná, temos o Programa de Desenvolvimento Educacional (PDE), regulamentado em 2010, o qual tem por objetivo proporcionar aos professores da rede pública estadual, que atuam na Educação Básica, conhecimento teórico-metodológico que os auxilie em mudanças da prática pedagógica. Segundo Paraná (2016, p.2), no âmbito desse programa, o conceito de formação continuada inclui: "O movimento permanente e sistemático de aperfeiçoamento dos professores da rede de ensino estadual, em estreita relação com as IES, com o objetivo de instituir uma dinâmica permanente de reflexão, discussão e construção do conhecimento sobre a realidade escolar".

As atividades do PDE são desenvolvidas em dois anos, sendo que no primeiro ano é proposto um modelo de formação continuada com cursos realizados nas universidades e faculdades públicas, o que proporciona o retorno dos professores às atividades acadêmicas. O docente da educação básica, que faz parte do Quadro Próprio do Magistério, possui um plano de carreira, regulamentado pela lei complementar $n^{\circ} 103$ - 15/03/2004. Ao cursar o PDE, o professor é promovido e consegue um aumento salarial. Sendo assim, o PDE possibilita ao professor, além da formação continuada, uma valorização econômica (Paraná, 2016).

Outro programa que possibilita o trabalho conjunto de professor universitário, professor de Ensino Médio e licenciandos, é o Programa Institucional de Bolsas de Iniciação à Docência (PIBID) ${ }^{1}$ :

Art. $3^{\circ}$ Os projetos apoiados no âmbito do PIBID são propostos por instituições de ensino superior (IES) e desenvolvidos por grupos de licenciandos sob supervisão de professores de educação básica e orientação de professores das IES.

Parágrafo único. O apoio do programa consiste na concessão de bolsas aos integrantes do projeto e no repasse de recursos financeiros para custear suas atividades.

Outro aspecto relacionado à formação de professores de Química é a profissionalização docente, pois a visão que se tem da profissão docente depende de como a atividade do professor é vista em sua formação. Dentro desse contexto, a separação que geralmente acontece entre as disciplinas específicas de Química e as pedagógicas nos cursos de licenciatura, onde muitas vezes é dada uma maior importância para as disciplinas específicas, contribui para uma desvalorização do professor, sendo esse um problema a ser investigado e superado (Maldaner, 2013).

Em síntese, nesta sessão abordou-se o entendimento de alguns autores a respeito da formação de professores, tendo esses referenciais teóricos auxiliado na interpretação dos artigos selecionados. A seguir, apresentamos detalhadamente qual foi a metodologia adotada para coleta e análise de dados e como essa foi utilizada na investigação, cujos resultados descrevemos neste artigo.

\section{Metodologia}

Considerando a questão de pesquisa deste artigo, optou-se pelos procedimentos e critérios inspirados na Análise Textual Discursiva, desenvolvida em torno de quatro momentos: desmontagem dos textos, estabelecimento de relações, capturando um novo emergente e processo auto-organizado (Moraes \& Galiazzi, 2011). As definições desses momentos estão descritas a seguir.

O primeiro - desmontagem dos textos -, consiste em examinar os materiais em seus detalhes, por meio de algumas etapas: leitura dos textos; o significado das leituras e os inúmeros sentidos; o corpus; as unidades de análise. Inicialmente, deve ser realizada a leitura do material utilizado na investigação. É importante destacar que os materiais textuais possuem um

\footnotetext{
${ }^{1}$ Que pode ser acessado em:

http://www.capes.gov.br/images/stories/download/legislacao/Portaria_096_18jul13_AprovaRegulamentoPIBID.pdf.
} 
conjunto de significantes e o investigador precisa atribuir a eles significados. Cada pesquisador pode atribuir significados diferentes, de acordo com os referenciais teóricos adotados. A emergência e a comunicação de novos sentidos e significados são o objetivo da análise.

O corpus representa o conjunto de textos selecionados para a investigação. Em seguida, inicia-se o processo da análise. Para isso é feita a desconstrução e unitarização dos textos e alguns elementos são destacados. A unitarização é dividida em três etapas: fragmentação dos textos e codificação de cada unidade; reescrita dos textos fragmentados de modo que assumam um significado, o mais completo possível; atribuição de um nome para cada unidade.

Nesta pesquisa, antes de iniciar o processo de análise foi definido o corpus composto por artigos publicados na QNESC, no período de 1995-2020, que abordavam a formação de professores de Química; na subseção a constituição do acervo contém uma descrição detalhada de como esse corpus foi selecionado. Após, iniciou-se o processo de análise, na qual foi feita a leitura desses artigos, a desconstrução dos textos, em que foram considerados fragmentos relevantes a respeito do tema formação de professores de Química, para a constituição das unidades de significados.

No segundo momento - estabelecimento de relações (categorização) -, o investigador busca construir relações entre as unidades de análise. Essas são classificadas de modo a compreender como esses elementos unitários podem ser reunidos na formação de categorias, que podem ser: a priori (quando são definidas em um momento anterior à interpretação dos dados) ou emergentes (aquelas que surgem durante o processo analítico). Nesta investigação, foram estabelecidas categorias a priori, com base nos estudos realizados por Silva e Queiroz (2016, 2017): formação inicial, formação continuada, profissionalização docente e prática pedagógica. Pelo fato dessas não terem sido suficientes para a classificação dos artigos, emergiram durante a análise as seguintes categorias: artigos que mesclam categorias e outras temáticas e a formação de professores. As definições dessas categorias a priori e emergentes, encontram-se na subseção categorias de análise.

O terceiro momento - capturando o novo emergente, provoca a impregnação nos materiais da análise, que possibilita a emergência de uma nova compreensão e resulta na construção de metatextos que, segundo Moraes e Galiazzi (2011, p.12), "representa um esforço de explicitar a compreensão que se apresenta como produto de uma nova combinação dos elementos construídos ao longo dos passos anteriores". Para tal captura, é necessário descrição e interpretação, com o intuito de produzir textos que possibilitem uma nova compreensão e teorização, a qual pode ser emergente, ou uma complementação de teorias já existentes. Para essa investigação, buscou-se construir uma análise que expressasse os sentidos lidos nos artigos a respeito da formação de professores de Química. Os metatextos estão descritos na seção de resultados e discussão, pois foram construídos durante a interpretação dos artigos selecionados e que constituem nosso corpus investigativo.

Os três primeiros momentos formam um ciclo que possibilita o quarto - um processo auto-organizado - o qual ocorre ao final da análise e possibilita que novas compreensões sejam evidenciadas.

Nas subseções: definição do corpus; categorias de análise; os artigos e a caracterização da formação de professores de Química, trouxemos esclarecimentos de como a Análise Textual Discursiva foi utilizada para o desenvolvimento desta pesquisa.

\subsection{Definição do corpus}

Antes de estabelecer o corpus, foi necessário constituir um acervo, o que exigiu a delimitação dos critérios de seleção. Para este caso, os periódicos selecionados deveriam apresentar: artigos publicados on-line, com acesso aberto e períodos de publicações próximos, no mínimo duas décadas de publicações. Esses critérios foram estabelecidos devido à área Ensino abranger 168 periódicos nos extratos elencados para a montagem do acervo desta pesquisa, ou seja, A1, A2 e B1 (segundo o Sistema de Avaliação Qualis (2014) utilizado pela Coordenação de Aperfeiçoamento de Pessoal de Nível Superior - CAPES). 
Por ser uma pesquisa específica, acerca do tema Formação de professores de Química, optou-se por escolher periódicos do Ensino de Ciências, em geral, e do Ensino de Química, em particular, e o período semelhante foi considerado como critério porque havia o intuito de comparar as publicações desses periódicos. De acordo com esses critérios, em um primeiro momento, foram selecionados para constituir a primeira versão do acervo os seguintes periódicos: Ciência \& Educação (A1) e Química Nova na Escola (B1). No entanto, após fazer o levantamento dos artigos que abordavam o tema formação de professores de Química, observou-se uma discrepância entre os dados dos dois periódicos, uma vez que a quantidade de artigos selecionados na Ciência \& Educação foi diferente e inferior ao do periódico Química Nova na Escola, sendo que no primeiro periódico, apenas 3,70\% dos artigos publicados faziam menção ao tema formação de professores de Química, enquanto que na Química Nova na Escola, 23,43\% foram referentes ao tema em questão.

Sendo assim, optou-se por desenvolver esta pesquisa com os artigos publicados no periódico Química Nova na Escola (QNESC), no período de 1995-2020.

Cabe destacar que a QNESC surgiu a partir de ideias de debates realizados no VII Encontro Nacional do Ensino de Química, que ocorreu em 1994, em que foi proposta a criação de uma revista para professores de Química. Dentro desse contexto, em 1995 foi publicado o primeiro número da revista pela Sociedade Brasileira de Química - SBQ, com o intuito de auxiliar o trabalho, a formação e a atualização dos professores de Química e proporcionar aos docentes um espaço de debates e reflexões a respeito do processo de ensino e aprendizagem de Química (Beltran, 1995).

Segundo Queiroz e Veras (2015), o sucesso da QNESC pode ser associado à utilização dos seus artigos em ambientes de ensino, onde contribui com o trabalho do professor de Química, pois suas publicações auxiliam os mesmos na elaboração e no desenvolvimento das suas aulas. Esses artigos são utilizados por professores da Educação Básica e na formação de professores de Química, em disciplinas de cursos de licenciatura. Consideração que também contribuiu para que desenvolvêssemos nossa pesquisa pautando-nos neste único periódico.

Tendo delimitado nosso acervo - todos os artigos da QNESC desde sua criação - foram estabelecidos os critérios utilizados na definição do corpus. Para a seleção dos artigos, utilizaram-se as seguintes palavras-chave: formação de professores; formação de professores de Química; formação docente; formação inicial; formação continuada, como termo de busca no campo de pesquisa do site da QNESC, considerando aqueles que continham pelo menos uma das palavras-chave estabelecidas no título, no resumo, nas palavras-chave ou no corpo do artigo. Além disso, fez-se a leitura dos títulos, possibilitando dessa forma um controle seletivo e legítimo do corpus. Diante desses critérios foram consultadas 80 revistas da QNESC com o total de 801 artigos publicados.

Após reunir todos os artigos, foi realizada a organização do material. Para isso fez-se a codificação dos artigos de acordo com o ano e a ordem na qual os mesmos foram selecionados. Por exemplo: 2010QNESC1, os quatro primeiros dígitos referem-se ao ano de publicação do artigo, neste caso 2010, QNESC refere-se ao periódico Química Nova na Escola e o último dígito corresponde à ordem em que os artigos foram numerados para facilitar a localização deles em um mesmo ano. Após a constituição do corpus $^{2}$, organização do material, leitura e desconstrução dos textos, iniciou-se o processo de categorização, as categorias utilizadas nesta pesquisa estão descritas no próximo tópico.

\subsection{Categorias de análise a priori}

Como indicado anteriormente, optou-se pelo uso de categorias a priori, estabelecidas a partir de uma adaptação do que Silva e Queiroz $(2016,2017)$ apresentaram em seus resultados, são elas: formação inicial; formação continuada; profissionalização docente e prática pedagógica. A descrição de cada uma dessas categorias foi apresentada no Quadro 1.

\footnotetext{
${ }^{2} \mathrm{O}$ título de cada artigo, juntamente com o volume, o número e as páginas da revista em que foi publicado, pode ser observado no anexo.
} 
Quadro 1 - Descrição das categorias estabelecidas a priori utilizadas para classificação dos artigos.

\begin{tabular}{|l|l|}
\hline \multicolumn{1}{|c|}{ Categorias } & \multicolumn{1}{c|}{ Descrição } \\
\hline Formação inicial & $\begin{array}{l}\text { Artigos que investigam a formação inicial de professores de Química, aspectos relacionados à } \\
\text { licenciatura, dentre estes: o currículo e a avaliação do curso, desenvolvimento de estágios, dentre } \\
\text { outros }\end{array}$ \\
\hline Formação continuada & $\begin{array}{l}\text { Artigos que apresentam como foco principal a investigação de programas e cursos de formação } \\
\text { continuada, como o desenvolvimento profissional e a reflexão crítica sobre a prática. }\end{array}$ \\
\hline $\begin{array}{l}\text { Profissionalização } \\
\text { docente }\end{array}$ & $\begin{array}{l}\text { Artigos que abordam aspectos relacionados ao professor e sua ação, como: identidade e concepções, } \\
\text { dentre outros aspectos relativos à profissionalização docente. }\end{array}$ \\
\hline Prática pedagógica & $\begin{array}{l}\text { Acomoda artigos que buscam investigar aspectos da prática docente relacionados com a escola e a } \\
\text { sala de aula. }\end{array}$ \\
\hline
\end{tabular}

Fonte: Autores.

Na categoria Formação inicial foram agrupados os artigos que argumentavam a respeito de investigações que destacavam aspectos relacionados aos cursos de licenciatura, por exemplo, momentos nos quais os professores em formação inicial realizaram estágios (Kassboehmer \& Ferreira, 2008). Além disso, foram incluídos artigos que apresentaram como objetivo investigar questões relativas à formação inicial, aos currículos e aos estudantes, sempre considerando a licenciatura em Química (André, 2009).

Na segunda categoria - Formação continuada - inserimos artigos que incluíam a investigação de tópicos resultantes de programas, reuniões e cursos de formação continuada.

Um trabalho que auxiliou na compreensão a respeito dessa categoria, foi o de Silva e Queiroz (2016), quando definem que "os programas de formação continuada possibilitam o desenvolvimento profissional e a atualização dos conhecimentos docentes e, ao propiciarem reflexão crítica sobre a prática, favorecem uma atuação profissional mais alinhada aos novos tempos" (Silva \& Queiroz, 2016, p.65).

Profissionalização docente (terceira categoria) - englobou artigos que tinham como objetivo analisar aspectos relacionados ao professor e sua ação, ou seja, dentro desse contexto encontra-se o profissional professor o qual, segundo Dassoler e Lima (2012, p.7),

[...] pode ser considerado como um teórico-prático que adquiriu por meio de muito estudo e pelo desenvolvimento de suas vivências em sala de aula, o status e a capacidade para realizar com autonomia, responsabilidade e ousadia sua função. Além disso, o profissional professor é também uma pessoa em evolução em que o saber da experiência lhe pode conferir maior autonomia profissional, juntamente com outras competências que viabilizam a sua profissão.

A profissionalização docente inclui o perfil profissional do professor, a identidade profissional, os conhecimentos e saberes dos professores e o desenvolvimento profissional, sendo que essas questões dependem do tipo de formação dos docentes (Gatti, 2016). Os conhecimentos e saberes adquiridos na formação são aperfeiçoados durante a prática docente. Considera-se que tanto a profissionalização docente quanto a formação fazem parte de um processo contínuo e inacabado (Dassoler \& Lima, 2012).

É necessário englobar na formação de professores uma reflexão a respeito da profissão docente. A profissionalização docente apresenta relação com três aspectos que precisam ser considerados na formação de professores. O desenvolvimento pessoal, trabalhado quando se busca a formação de um professor reflexivo. O desenvolvimento profissional, este define que não é possível transformar o professor sem transformar também a escola, sendo necessário considerar o desenvolvimento organizacional, ou seja, produzir a escola (Nóvoa, 1992).

Para quarta categoria - Prática pedagógica - foram selecionados os artigos que traziam resultados cujo objetivo da pesquisa era a prática pedagógica, ou seja, procuraram investigar a formação inicial e continuada de professores em situações 
práticas, no contexto da sala de aula, ou seja, enquanto os licenciandos realizavam estágios nas escolas. Além disso, consideramos também aqueles que buscavam investigar a ação reflexiva do professor a respeito da sua prática e da prática de outrem.

Dos 205 artigos analisados, 113 deles não puderam ser acomodados nas quatro categorias assumidas a priori. Fato que nos levou à necessidade da emergência de outras categorias, que no nosso caso foram duas: a primeira delas denominada por Artigos que mesclam categorias, pois havia artigos que traziam informações sobre pesquisas que apresentaram como objetivo investigar aspectos relacionados a mais do que uma das possibilidades anteriores; a segunda categoria emergente intitulada - Outras temáticas e a formação de professores - em que alocamos os artigos (constituintes do corpus, mediante os critérios assumidos para seleção), mas que apresentaram outro tema de pesquisa como objetivo principal, entre eles: análise de livro didático, proposta de uma metodologia de ensino. Cabe esclarecer que neste conjunto estão os artigos em que a formação do professor de Química foi abordada como consequência e não como foco de pesquisa.

Em seguida, foi feita a leitura e a categorização, na qual foram reunidos elementos semelhantes com a finalidade de organizar nas descrições para a elaboração do novo emergente deste processo auto-organizado. Informações relativas e esse momento da pesquisa, os resultados a que chegamos e algumas discussões, foram inseridos na próxima seção.

\section{Resultados e Discussão}

Do total de 801 artigos publicados na QNESC, no período de 1995 a 2020 - 26 anos, foram selecionados 205 para análise. Após a seleção, buscou-se investigar: i) a quantidade de artigos que foram publicados em cada ano. ii) o significado dado à formação de professores no contexto do Ensino de Química, em termos de publicações.

A Tabela 1 apresenta o ano de publicação e o volume da revista QNESC, a quantidade de artigos publicados nas revistas; o número e a porcentagem de artigos trazem a formação de professores de Química como foco, em relação ao total de artigos publicados na QNESC, de acordo com o respectivo ano (1995-2020) da publicação. 
Tabela 1 - Organização dos artigos publicados com o tema formação de professores de Química da Revista Química Nova na Escola ano a ano.

\begin{tabular}{|c|c|c|c|c|}
\hline $\begin{array}{c}\text { Ano da } \\
\text { publicação }\end{array}$ & $\begin{array}{c}\text { Volume da } \\
\text { revista }\end{array}$ & $\begin{array}{c}\text { Total de artigos } \\
\text { publicados }\end{array}$ & $\begin{array}{c}\text { Artigos sobre formação de } \\
\text { professores de Química }\end{array}$ & $\begin{array}{l}\text { Artigos sobre formação de } \\
\text { professores de Química (\%) }\end{array}$ \\
\hline 1995 & $1 ; 2$ & 23 & 2 & 8,69 \\
\hline 1996 & $3 ; 4$ & 19 & 2 & 10,53 \\
\hline 1997 & $5 ; 6$ & 20 & 2 & 10,00 \\
\hline 1998 & $7 ; 8$ & 23 & 0 & 0 \\
\hline 1999 & $9 ; 10$ & 25 & 4 & 16,00 \\
\hline 2000 & $11 ; 12$ & 21 & 1 & 4,76 \\
\hline 2001 & $13 ; 14$ & 22 & 1 & 4,54 \\
\hline 2002 & $15 ; 16$ & 20 & 2 & 10,00 \\
\hline 2003 & $17 ; 18$ & 23 & 3 & 13,04 \\
\hline 2004 & $19 ; 20$ & 22 & 2 & 9,09 \\
\hline 2005 & $21 ; 22$ & 21 & 0 & 0 \\
\hline 2006 & $23 ; 24$ & 22 & 1 & 4,54 \\
\hline 2007 & $25 ; 26$ & 22 & 2 & 9,09 \\
\hline 2008 & $27 ; 28 ; 29 ; 30$ & 41 & 9 & 21,95 \\
\hline 2009 & 31 & 41 & 9 & 21,95 \\
\hline 2010 & 32 & 34 & 8 & 23,53 \\
\hline 2011 & 33 & 32 & 8 & 25,00 \\
\hline 2012 & 34 & 32 & 18 & 56,25 \\
\hline 2013 & 35 & 35 & 12 & 34,28 \\
\hline 2014 & 36 & 36 & 21 & 58,33 \\
\hline 2015 & 37 & 65 & 25 & 38,46 \\
\hline 2016 & 38 & 48 & 21 & 43,75 \\
\hline 2017 & 39 & 40 & 15 & 37,50 \\
\hline 2018 & 40 & 34 & 6 & 17,65 \\
\hline 2019 & 41 & 42 & 19 & 45,24 \\
\hline 2020 & 42 & 38 & 12 & 31,58 \\
\hline Total geral & & 801 & 205 & 25,59 \\
\hline
\end{tabular}

Fonte: Autores.

Pode-se afirmar que na Tabela 1 tem-se um mapeamento da produção bibliográfica da QNESC (1995-2020), quanto ao tema formação de professores de Química. Nota-se que é relevante o número de artigos que abordam esse tema, uma vez que 25,59\% dos 801 artigos publicados na QNESC apresentaram resultados ou intenções sobre o tema.

Ao fazer uma interpretação temporal, foi possível perceber que publicações a respeito da formação de professores de Química estiveram presentes desde o primeiro número no ano de 1995, como mostra a Tabela 1 e o Gráfico 1, com exceção dos anos 1998 e 2005.

Ao comparar o percentual de artigos que investigaram a formação de professores de Química em todo o período considerado, notou-se um aumento significativo de artigos a respeito do tema a partir do ano de 2008. Ao fazer uma análise geral, foi possível observar que 89,27\% dos artigos que abordaram a formação de professores de Química foram publicados no período de 2008-2020. Por meio do Gráfico 1 é possível ter uma melhor visualização desses resultados. 
Gráfico 1 - Quantidade de artigos do corpus no período 1995-2020.

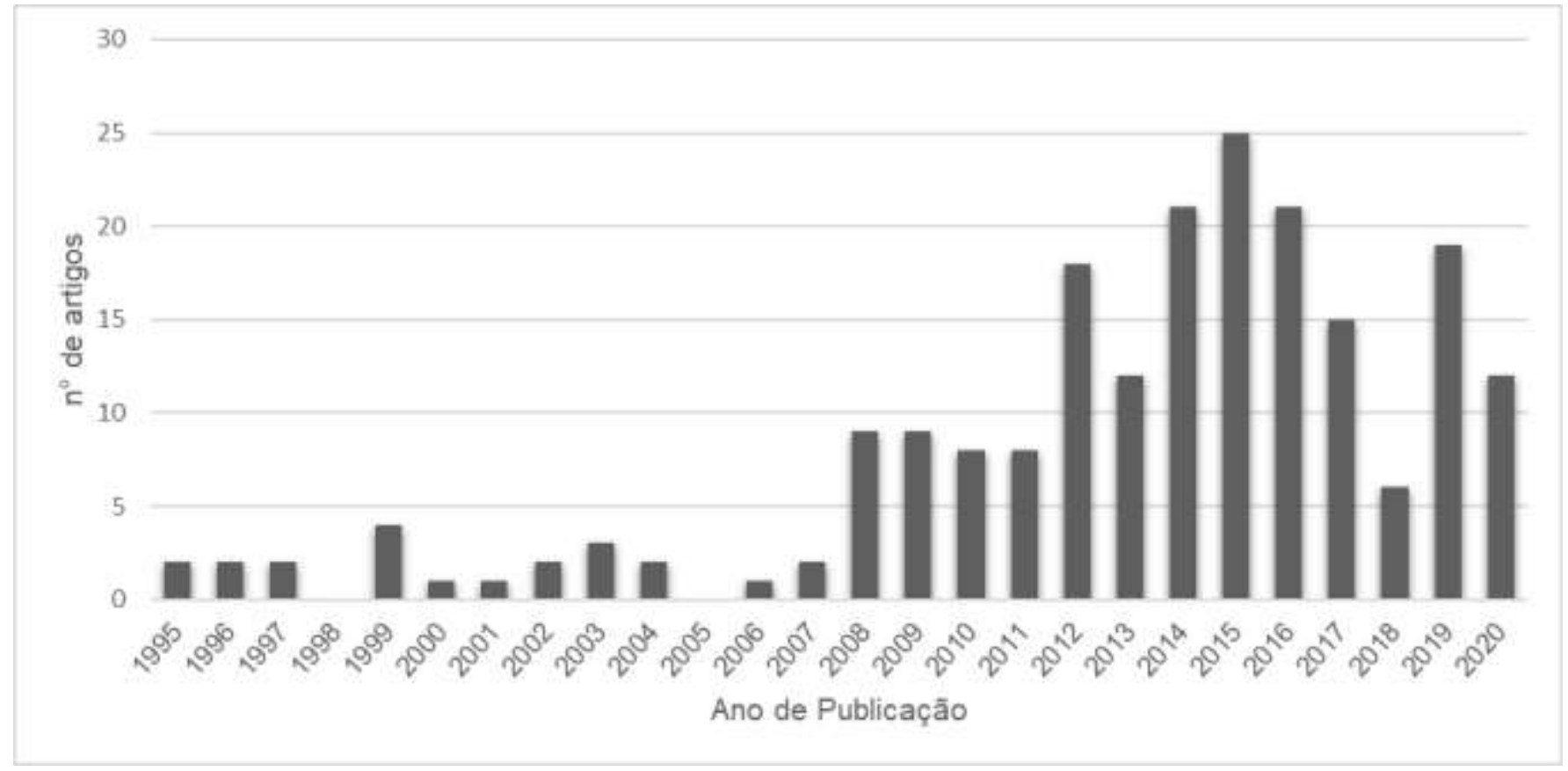

Fonte: Autores.

Um aspecto que pode ter influenciado este crescimento foi o aumento do número de revistas publicadas, pois até 2007, dois números da QNESC eram publicados por ano e no período de 2008 até 2020 foram publicados quatro números anualmente. Além disso, em 2015, tiveram dois números especiais, ou seja, neste ano foram publicados seis números da QNESC. Esse aumento impulsiona a quantidade de artigos publicados, o que pode ter influenciado nos resultados obtidos.

A quantidade de cursos de Química disponíveis no País pode também ter influenciado neste aumento, pois segundo Brasil (2017), em 2007 havia 153 cursos de graduação de formação inicial de professores de Química no País, já em 2020 eram 343 cursos. Sendo assim, no período de 2008-2020 houve um aumento de 190 cursos de Química na modalidade licenciatura. Logo, é possível que o envolvimento maior de docentes e estudantes com esses cursos pode ter despertado um interesse maior pelo tema de pesquisa formação de professores de Química e, também, influenciado no número de publicações a respeito desse tema na revista QNESC.

Existem, ainda, algumas questões qualitativas que podem estar associadas ao maior número de artigos relacionados com o tema formação de professores de Química, entre os anos de 2008 e 2017, entre eles: o tema da capa da revista de volume 31, número 2, publicada em maio de 2009 - Formação de Professores de Química no Brasil -, um número voltado, especialmente, à formação dos profissionais educadores de Química.

Outro aspecto que se pode relacionar a esse aumento significativo foi o lançamento do Programa Institucional de Bolsa de Iniciação à Docência - PIBID que, segundo a CAPES (2013), teve início com atividades nas universidades federais em 2009, e nas universidades estaduais em 2010, e desde então está presente como um programa de incentivo ao magistério e possibilita um aprimoramento na formação de professores. Sendo assim, considera-se que o envolvimento de docentes universitários e da Educação Básica e estudantes da graduação, com o PIBID, tenha incentivado o desenvolvimento de pesquisas na área de formação de professores.

Inclusive, ao observar os dados da Tabela 1 é possível notar um avanço no número de artigos relacionados à formação de professores de 2011 (25,00\%) para 2012 (56,25\%), do total de artigos selecionados. Pode-se associar esse aumento com as publicações referentes ao PIBID, uma vez que, em 2012, foi lançada uma chamada para publicação de artigos a respeito do PIBID. Ao analisar os artigos de 2012, que abordaram o tema formação de professores, tem-se que $61,11 \%$ dos 18 artigos 
selecionados estavam relacionados ao PIBID. Lembrando que esse programa se destacou no campo das políticas públicas educacionais, o que possibilita o envolvimento de professores e o despertar de pesquisadores.

Ao buscar na literatura trabalhos de caráter bibliográfico, encontrou-se um trabalho de Mortimer et al. (2015), que teve por objetivo analisar a produção da seção "Pesquisa em Ensino de Química" da QNESC, no período de 2005 a 2014. Neste artigo, observou-se um aumento significativo de artigos publicados nesta seção nesse período, ao comparar com a quantidade de trabalhos presentes nesta mesma seção nos anos de 1995 a 2004. Os autores associam esse crescimento ao aumento dos cursos de pós-graduação, fator esse que também pode ter impulsionado as publicações sobre formação de professores de Química no período de 2008 a 2016, pois a área de Ensino de Ciências tinha, em 2004, 18 programas de pósgraduação em Ensino de Ciências e Matemática no Brasil. No ano de 2013, já transformada em área de Ensino, essa quantidade era de 104 programas. Esse aumento na quantidade de cursos de pós-graduação Stricto Sensu, pode-se estar associado ao aumento de publicações relacionadas a essa temática.

Diante desses resultados, com relação à quantidade de artigos com foco na formação de professores de Química, publicados no decorrer do período de 1995-2020, buscou-se investigar se essa era uma característica apenas do Ensino de Química ou se apresentava aspectos comuns com publicações de outras áreas. Nesse movimento, deparamo-nos com a pesquisa de M. Passos (2009), relacionada à área de Educação Matemática, que teve por objetivo investigar nos artigos selecionados a respeito da formação de professores de Matemática o que é ou quem é o professor de Matemática para os autores desses artigos. Encontramos, também, a investigação de A. Passos (2009), relacionada à formação de professores no Ensino de Ciências, com o objetivo de apontar alguns significados do campo formação e buscar caracterizar este foco de estudo, na perspectiva de artigos publicados em periódicos nacionais da área de Ensino de Ciências.

Ao fazer uma comparação com os resultados encontrados nesses trabalhos na área de Educação Matemática e Ensino de Ciências, com os dados desse artigo na área de Ensino de Química, foi possível realizar alguns apontamentos. Por exemplo, embora a coleta de dados tenha sido feita em períodos diferentes, os intervalos de tempo não são discrepantes. Vejamos: A. Passos (2009) dedicou-se a 29 anos de publicações (1979-2007); M. Passos (2009) investigou artigos no período de (19762007), o que equivale a 32 anos de publicações; no presente artigo, o levantamento de dados foi realizado de 1995 a 2020, ou seja, 26 anos. Quanto aos percentuais: na área de Ensino de Ciências, A. Passos (2009) identificou que 22\% do total de artigos que faziam parte do seu acervo eram referentes ao tema formação de professores; M. Passos (2009), também mostra que 19\% do total de artigos pesquisados abordaram assuntos relacionados à formação de professores; em nossa pesquisa identificamos que, aproximadamente, 26\% dos artigos correspondem ao tema formação de professores de Química, o que mostra a relevância do tema para o Ensino de Ciências, a Educação Matemática e o Ensino de Química.

Outra característica comum identificada entre as três áreas, pelos levantamentos realizados, é que a maioria dos artigos selecionados a respeito do tema formação de professores foi publicada nos últimos oito anos do período selecionado para investigação. Essas informações foram organizadas Tabela 2.

Tabela 2 - Semelhança quantitativa para as três áreas dos artigos referentes à formação de professores.

\begin{tabular}{c|c|c|c}
\hline Área de pesquisa & $\begin{array}{c}\text { Período de } \\
\text { investigação }\end{array}$ & $\begin{array}{c}\text { Período dos últimos 8 anos } \\
\text { selecionados para estudo }\end{array}$ & $\begin{array}{c}\text { Artigos de formação de professores } \\
\text { nos últimos 8 anos }\end{array}$ \\
\hline Educação Matemática & $1976-2007$ & $2000-2007$ & $64 \%$ \\
\hline Ensino de Ciências & $1979-2007$ & $2000-2007$ & $66 \%$ \\
\hline Ensino de Química & $1995-2020$ & $2013-2020$ & $64 \%$ \\
\hline
\end{tabular}

Fonte: Autores. 
Com essa interpretação dos dados foi possível observar que, embora essas pesquisas tenham sido realizadas em períodos diferentes, existe uma proporcionalidade no percentual de artigos referentes à formação de professores nos últimos 8 anos pesquisados nas três áreas, Educação Matemática, Ensino de Ciências e Ensino de Química, o que nos remete a considerar que o interesse pela temática formação de professores passou a ser maior com o decorrer do tempo nessas três áreas de pesquisa.

Com o intuito de caracterizar o tema formação de professores de Química, foi feita uma classificação de acordo com as categorias utilizadas por Silva e Queiroz (2016). No entanto, essas não foram suficientes para esta pesquisa, sendo assim, emergiram outros focos de pesquisa e os artigos que não se enquadraram nas categorias a priori foram classificados nesses focos emergentes. Além disso, foram criadas subcategorias. No Quadro 2 apresenta-se a distribuição dos 205 artigos selecionados nas 6 categorias, as subcategorias e a quantidade de artigos alocados em cada uma delas. Cabe destacar que a elaboração das subcategorias contribuiu com a caracterização de cada categoria, que, por conseguinte, ajudou-nos responder à nossa questão de pesquisa. 
Quadro 2 - Organização geral do corpus analisado nas categorias de formação de professores.

\begin{tabular}{|c|c|c|c|}
\hline Categorias & Subcategorias & Quantidade de artigos & Total \\
\hline \multirow{9}{*}{ Formação inicial } & Contribuir na formação & 15 & \multirow{9}{*}{53} \\
\hline & PIBID & 15 & \\
\hline & Currículo & 11 & \\
\hline & Estágio & 5 & \\
\hline & Leitura & 2 & \\
\hline & Pesquisa & 2 & \\
\hline & Análise do curso & 1 & \\
\hline & Investigar a formação & 1 & \\
\hline & Investigar a aprendizagem & 1 & \\
\hline \multirow{6}{*}{ Formação continuada } & Programas & 3 & \multirow{6}{*}{9} \\
\hline & Ambientes virtuais & 2 & \\
\hline & Concepções & 1 & \\
\hline & Processos formativos & 1 & \\
\hline & Projetos & 1 & \\
\hline & Reuniões & 1 & \\
\hline \multirow{5}{*}{ Profissionalização docente } & Saberes docentes & 5 & \multirow{5}{*}{14} \\
\hline & Concepções & 4 & \\
\hline & Identidade & 3 & \\
\hline & História e experiências pessoais & 1 & \\
\hline & Gênero & 1 & \\
\hline \multirow{3}{*}{ Prática pedagógica } & Práticas de ensino & 9 & \multirow{3}{*}{16} \\
\hline & Ação reflexiva & 6 & \\
\hline & Metodologias de ensino & 1 & \\
\hline \multirow{6}{*}{$\begin{array}{l}\text { Primeira categoria emergente - artigos } \\
\text { que mesclam categorias }\end{array}$} & Formação inicial e continuada & 6 & \multirow{6}{*}{22} \\
\hline & Formação inicial e profissionalização docente & 5 & \\
\hline & Formação continuada e prática pedagógica & 3 & \\
\hline & $\begin{array}{l}\text { Formação inicial, formação continuada e prática } \\
\text { pedagógica }\end{array}$ & 3 & \\
\hline & Profissionalização docente e prática pedagógica & 3 & \\
\hline & Formação inicial e prática pedagógica & 2 & \\
\hline \multirow{5}{*}{$\begin{array}{l}\text { Segunda categoria emergente - outras } \\
\text { temáticas e a formação de professores }\end{array}$} & Outro tema & 44 & \multirow{5}{*}{91} \\
\hline & Palavras-chave & 29 & \\
\hline & Investigação bibliográfica & 9 & \\
\hline & PIBID & 6 & \\
\hline & Outra área & 3 & \\
\hline & & Total & 205 \\
\hline
\end{tabular}

Fonte: Autores.

O Quadro 2 mostra que 53 artigos $(25,85 \%)$ foram classificados na categoria - Formação inicial. Esses apresentaram como objetivo investigar a formação inicial de professores de Química. Segundo Galiazzi e Moraes (2002), Nascimento et al. (2010); Zimmermann e Bertani (2003), existem diversos problemas nos cursos de licenciatura. Sendo assim, considera-se importante que sejam desenvolvidas essas pesquisas para identificar essas dificuldades e buscar alternativas para resolvê-las.

Com o intuito de entender o que tem sido publicado acerca do tema formação inicial de professores de Química, os 53 artigos alocados na categoria foram classificados em subcategorias, que foram denominadas considerando aspectos destacados 
a respeito da formação inicial nos artigos: os que apresentaram propostas relacionadas à Contribuição na formação e ao PIBID, ambas apresentaram 28,30\% de artigos cada uma; 20,76\% investigaram o Currículo; 9,43\% dizem respeito ao Estágio; os outros 13,21\% estão relacionados à Leitura, Pesquisa, Análise do curso, Investigar a formação e Investigar a aprendizagem, sempre durante a formação inicial.

Com esses resultados, foi possível perceber a predominância de publicações que destacaram contribuições para a formação dos licenciandos e relacionadas ao Programa PIBID. Em tais artigos têm-se resultados de investigações sobre propostas de atividades, desenvolvimento de metodologias e/ou abordagens de ensino alternativas na formação dos licenciandos. Para exemplificar nossas alocações, nessas duas subcategorias, trazemos um fragmento do artigo (2003QNESC3) que nos chamou a atenção:

[...] contribuir na formação inicial do professor de Química, através da participação de um aluno de licenciatura em Química (UERJ) no preparo e realização da aula experimental (p.28).

E outro de (2012QNESC2), que tem por foco o PIBID "abordar a contribuição das atividades do subprojeto do PIBID do Instituto de Química da Unesp de Araraquara para a formação dos licenciandos” (p.184).

Outro aspecto investigado nos artigos dessa categoria é a análise de currículos, em que são abordados currículos dos cursos de licenciatura, como mostra o fragmento de (2008QNESC3): "Apresentar os resultados de uma análise documental realizada em cinco cursos de Licenciatura em Química da região Sul do Brasil, identificar e analisar, nos respectivos currículos, o enfoque dado aos problemas ambientais" (p.30).

Cinco artigos investigaram os estágios, essas pesquisas abordaram experiências de licenciandos durante o estágio supervisionado. Para exemplificar nossa análise trouxemos (2013QNESC3): "Refletir sobre experiências vivenciadas no cotidiano escolar por uma estudante de licenciatura em química durante o estágio supervisionado" (p.283).

Os outros artigos investigaram os seguintes aspectos relacionados à formação inicial de professores: o tipo de leitura que os licenciandos de um curso de licenciatura fazem; a importância dos futuros docentes realizarem pesquisas; a qualidade de um curso de licenciatura; a formação que os licenciandos tiveram; e a aprendizagem durante a realização de uma atividade em uma disciplina. Como mostram alguns exemplos, das propostas desses artigos: "Investigar as leituras que estudantes do curso de Licenciatura em Química - na modalidade a distância - afirmam fazer" (p.235) (2009QNESC7). E "investigar a constituição de professores/pesquisadores ao fazer pesquisa no componente curricular de Monografia em um curso de Química-Licenciatura” (p.170) (2017QNESC4).

Na segunda categoria - Formação continuada - foram classificados 9 artigos, que correspondem a 4,39\% do total de trabalhos investigados. Com esse resultado é possível destacar que houve uma produção maior de artigos que pesquisou a formação inicial de professores, do que abordando a formação continuada. Esse resultado foi também observado por Silva e Queiroz (2016), que fizeram um levantamento em dissertações e teses, no qual encontraram um percentual maior de pesquisas voltadas para a formação inicial do que para a formação continuada de professores de Química.

Esse é um fator preocupante, uma vez que, segundo Silva e Bastos (2012), a formação inicial é apenas uma das fases de desenvolvimento profissional do professor e apresenta limitações, o que torna necessário o envolvimento deste em processos de formação continuada.

Além disso, Silva e Nunes (2020) destacam que, apesar da formação continuada docente fazer parte das políticas educacionais do País e garantir que todos os profissionais da Educação Básica tenham acesso à formação continuada, segundo pesquisas apenas 35\% dos docentes da educação básica afirmaram ter recebido esse tipo de formação. Considera-se que o desenvolvimento de pesquisas relacionadas a esse tema pode contribuir para avanços relacionados à formação continuada, consequentemente ampliar o desenvolvimento de cursos destinados ao professor da Educação Básica, para que esse tenha 
oportunidades de ampliar e atualizar seus conhecimentos, o que possibilita um aperfeiçoamento profissional e resultará na qualidade do processo de ensino e aprendizagem. Sendo assim, considera-se que mais pesquisas relacionadas a esse tema precisam ser desenvolvidas.

Os 9 artigos analisados com foco na formação continuada investigaram os seguintes temas: 33,34\% correspondem a programas de formação continuada; 22,22\% estão relacionados à análise de ambientes virtuais; e os outros 44,44\% abordam processos formativos, projetos, concepções a respeito da formação continuada e reuniões.

Neste caso, predominaram pesquisas referentes a programas, ou seja, três dos nove artigos alocados nessa categoria investigaram programas de formação continuada, como mostra a proposta de uma dessas pesquisas, "investigar o Projeto Folhas como proposta de formação continuada de professores dentro de um programa da Secretaria de Estado da Educação do Paraná, que teve início em 2004 e está em execução” (p.96) (2009QNESC3).

Outro tema encontrado nessa categoria foi a análise de ambientes virtuais propostos para a formação continuada de professores como "descrever a análise de um portal eletrônico ou website (INTERATIVO!) destinado à formação continuada de professores de Química" (p.249) (2010QNESC2).

Devido à quantidade de tecnologias que os estudantes têm contato atualmente, considera-se que esse tipo de trabalho é de suma importância para que o professor se atualize e tenha assim a possibilidade de utilizar essas tecnologias que teve contato durante esse processo de formação em alguns momentos de suas aulas com seus estudantes.

Os outros artigos dessa categoria investigaram: como ocorre um processo de formação continuada; concepções a respeito da formação continuada; projetos e reuniões de formação continuada. A seguir são apresentados exemplos das propostas desses artigos: "Entender a realidade de atuação e dos processos formativos de três professores de Química do ensino médio, únicos em suas escolas e municípios no interior do RS" (p.215) (2015QNESC12). E "experiência de reuniões de formação continuada, na qual o professor não é objeto do planejamento do trabalho, mas agente ativo desse processo resgatar, no professor, o papel de sujeito do processo do conhecimento" (p.13) (1996QNESC1).

Na categoria Profissionalização docente foram dispostos 14 artigos, que correspondem a 6,83\% do total de artigos selecionados para análise. Com esse resultado, foi possível perceber que poucos artigos trazem argumentações que vinculam formação de professores de Química com a profissão docente. Os temas, que sustentam nossas subcategorias, referem-se: 35,72\% aos saberes docentes; $28,57 \%$ a concepções docentes a respeito de conceitos de Química; $21,43 \%$ à identidade docente; $14,28 \%$ estavam relacionados a gênero e histórias e experiências pessoais.

Na sequência inserimos alguns fragmentos que ilustram as interpretações e as alocações realizadas na categoria e suas subcategorias.

[...] apresentar a análise dos saberes docentes mobilizados pela tríade de professores de química de deficientes visuais (professores formadores, professores em formação inicial e professores em formação continuada) no processo de construção de um diário virtual coletivo. (p.61) (2014QNESC4)

[...] apresentar as concepções de professores de Química de uma escola localizada no município do Rio de Janeiro, sobre o potencial de uma prática de volumetria, empregada para determinar a acidez de refrigerantes e inserida na aplicação da aprendizagem baseada em problemas para promover o ensino interdisciplinar. (p.112) (2015QNESC2)

Apresentar resultados parciais de uma pesquisa de mestrado desenvolvida com alunos do Programa de Licenciatura Especial da UFBA, os quais são professores do Ensino Médio do interior da Bahia... discutir questões relacionadas à construção da identidade e ao desenvolvimento profissional de um dos professores do grupo. (p.13) (2007QNESC1)

[...] argumentar em favor da importância da teoria curricular na formação de professores e demonstrar como nossas histórias e experiências pessoais podem constituir-se em poderosos catalisadores de reflexões sobre currículo. (p.23) (1999QNESC1) 
[...] esboçar um quadro evidenciando aspectos e tendências das discussões de Gênero nas pesquisas em Formação Docente em Educação em Ciências no Brasil de 2005 a 2017. (p.98) (2019QNESC2)

$\mathrm{Na}$ quarta categoria - Prática pedagógica - foram alocados 16 artigos, que correspondem a 7,80\% do total de artigos encontrados a respeito do tema formação de professores de Química. Segundo Lôbo e Moradillo (2003), essa formação depende de muitos aspectos, que vão além do conhecimento do conteúdo, ou seja, inclui questões relacionadas à prática pedagógica, que aborda assuntos da atividade docente em sala de aula. Na análise feita por Silva e Queiroz (2016), de dissertações e teses que abordaram o tema formação de professores de Química, também predominaram pesquisas que abordaram a formação inicial e continuada. Com isso, aponta-se para a necessidade de investigações que relacionem a formação de professores com a profissionalização docente e com a prática pedagógica.

Observando as percentagens temos que: 56,25\% investigaram as práticas de ensino; 37,50\% abordaram a ação reflexiva e 6,25\% apresentaram relação com metodologias de ensino. Com esses resultados foi possível perceber que a maioria dos artigos dessa categoria apresentaram como assunto as práticas de ensino, ou seja, analisaram a formação inicial/continuada de professores em situações práticas, nas quais professores em formação desenvolveram atividades em sala de aula, como mostra a proposta de um dos artigos: "Relatar uma atividade experimental, desenvolvida por dois licenciandos em uma escola pública de Florianópolis (SC)” (p.278) (2015QNESC21).

Com relação aos artigos que abordaram a ação reflexiva da formação docente, foi possível notar que os autores buscaram investigar aspectos relacionados a reflexão de questões importantes de serem trabalhadas na formação de professores, para solucionar problemas da sala de aula, como mostra o exemplo, "contribuir para a reflexão sobre a formação docente, destacando a importância das questões epistemológicas para uma formação mais crítica e menos tecnicista" (p.39) (2003QNESC2).

Um artigo apresentou metodologias de ensino desenvolvidas para contribuir com a formação de professores e auxiliar nas suas práticas pedagógicas, como mostra a proposta,

Com a crescente presença de sujeitos com deficiência em turmas de ensino regular, faz-se necessário o (re)pensar de práticas docentes, que contribuam para a inclusão desses alunos [...] apresentar metodologias de ensino que possam contribuir nos processos de ensino e aprendizagem em química, em turmas de ensino regular com alunos com síndrome de Asperger. (p.69) (2020QNESC3)

Além disso, foi possível observar que 22 artigos (10,73\%) apresentavam como objetivo principal investigar temas relacionados a mais do que uma das categorias mencionadas anteriormente, sendo assim, estes foram classificados em uma nova categoria - Artigos que mesclam categorias.

Com o intuito de saber quais foram os temas investigados em conjunto, esses artigos foram classificados nas seguintes subcategorias: $27,27 \%$ abordaram formação inicial e continuada; $22,72 \%$ dos artigos investigaram formação inicial e profissionalização docente; cada um dos temas a seguir contribuiu com 13,64\% dos artigos dessa categoria, formação continuada e prática pedagógica; formação inicial, formação continuada e prática pedagógica; profissionalização docente e prática pedagógica; e 9,09\% estavam relacionados à formação inicial e prática pedagógica.

Sendo assim, a maioria dos artigos que abordaram mais de um tema, investigaram formação inicial e continuada, ou seja, apresentaram como foco de pesquisa tanto a formação inicial quanto a formação continuada de professores, como mostra a proposta de um artigo "discutir a influência do PIBID na formação inicial e continuada de professores de Química" (p.44) (2014QNESC7). Essas pesquisas mostraram que foram desenvolvidos trabalhos que visavam investir em conjunto na formação inicial e continuada de professores de Química. Segundo Silva et al. (2008), esse tipo de trabalho pode contribuir para uma melhoria da formação de professores. 
Outros temas abordados em conjunto foram profissionalização docente e prática pedagógica. Nesse caso foram incluídos os artigos que investigaram tanto a profissionalização docente quanto a prática pedagógica. $\mathrm{O}$ exemplo destaca o que afirmamos: "Apresentar reflexões e discussões sobre o dia a dia na sala de aula de três professoras em formação continuada sobre algumas de suas ações docentes no Ensino Médio” (p.14) (1999QNESC3).

Além disso, foram encontrados artigos que apresentaram como foco principal de pesquisa investigar a formação inicial, a profissionalização docente, a prática pedagógica; a formação continuada, conforme mostrado na proposta de alguns desses artigos,

[...] investigar como a identidade docente vem sendo construída por três licenciandas em Química do IFRJ por meio dos significados que atribuem ao ser professor e ao seu processo formativo e, paralelamente, como o PIBID estaria envolvido nesse processo. (p.305) (2014QNESC5)

[...] apresentar uma experiência desenvolvida pelo grupo PIBID-Química/Biologia na Faculdade de Educação da UFMG [...] enfocar as ações executadas durante o projeto Água em foco: qualidade de vida e cidadania, desenvolvido em escolas das redes pública e particular de Minas Gerais desde 2004. Apresentar esse projeto como uma atividade de formação que envolve também os estudantes do Ensino Médio. Entender como o projeto se desenvolve; como acontece a participação dos envolvidos e como um projeto pode favorecer a formação dos licenciados. (p.240) (2012QNESC7)

Com esses resultados, foi possível perceber que alguns autores se preocuparam em investigar, em uma única pesquisa, mais que um foco temático relacionado à formação de professores de Química.

Por fim, na sexta categoria - Outras temáticas e a formação de professores - temos 91 artigos, que correspondem a $44,40 \%$ dos artigos selecionados para análise. Nessa categoria foram alocados trabalhos, que foram incluídos no corpus por conter pelo menos uma das palavras-chave utilizadas no levantamento, no entanto, no momento em que foi feita a análise, foi possível perceber que estes artigos não apresentavam como objetivo principal investigar a formação de professores de Química. Pelo fato desses terem sido incluídos no levantamento, optou-se por mantê-los no corpus e então foi feita uma análise com o intuito de entender qual a relação desses artigos com a formação de professores de Química.

Para um melhor entendimento foi feita uma classificação em subcategorias: 48,35\% dos artigos dessa categoria abordaram pesquisas com outros temas e a relação com a formação de professores; 31,87\% mencionaram palavras-chave; 9,89\% apresentaram pesquisas bibliográficas; 6,59\% abordaram o PIBID; e 3,30\% investigaram outra área.

No caso dessa categoria, predominaram artigos que abordaram outro tema e a relação com a formação de professores, ou seja, apresentaram como objetivo principal investigar outro tema de pesquisa, por exemplo, foram encontrados artigos que buscaram pesquisar estratégias de ensino, experimentação no Ensino de Química, livros didáticos, aprendizagem dos estudantes, dentre outros. E apresentaram uma discussão da relação desses temas com a formação de professores de Química, como mostra a proposta de um dos artigos "apresentar possíveis compreensões de interdisciplinaridade nas questões de Química do Novo ENEM referentes aos anos de 2009 a 2013” (p.112) (2016QNESC12).

Outro aspecto encontrado foram as palavras-chave, que nesse caso são artigos que investigaram outro tema de pesquisa, mas mencionaram algumas vezes as palavras-chave: formação de professores, formação inicial e formação continuada, utilizadas na coleta de dados. Porém, o tema formação de professores de Química não foi abordado e discutido. A seguir é apresentada a proposta de um desses artigos, cujo objetivo era discutir outro tema "fazer uma análise de textos que abordam aspectos relacionados ao uso dos termos cotidiano e contextualização no ensino de Química, procurando esclarecimentos acerca dos pressupostos epistemológicos e pedagógicos relacionados ao ensino dessa disciplina” (p.84) (2013QNESC12). 
Como o critério adotado para compor o corpus foi selecionar os artigos que apresentaram ao menos uma das palavraschave utilizadas no levantamento, os artigos classificados nessa categoria foram incluídos no corpus, e optou-se por não excluí-los. Além disso, esses mostraram uma característica a respeito dos trabalhos publicados na revista QNESC e a relação com o tema formação de professores, que mesmo não sendo essa a temática principal do artigo, diversas vezes são mencionadas palavras referentes a essa formação.

Com relação à investigação bibliográfica, são artigos que tinham por objetivo investigar a respeito de temas que foram publicados em revistas e mencionaram o que foi encontrado de formação de professores ou a relação dessas publicações com esse tema, como a seguir:

[...] fazer uma análise da produção dos últimos 10 anos da seção "Pesquisa em Ensino de Química" da Química Nova na Escola [...] sobre o perfil profissional dos autores, a temática dos artigos, os referenciais teóricos, as metodologias utilizadas e os objetivos das pesquisas. (p.188) (2015QNESC16)

Além desses, foram encontrados artigos que investigaram o PIBID, mas o objetivo era pesquisar a aprendizagem dos estudantes das escolas e não a formação de professores, como mostra a proposta de um desses artigos "verificar a influência do PIBID/Química da UFRGS sobre o desempenho de um grupo de alunos do Ensino Médio" (p.157) (2016QNESC5).

Os artigos classificados em outra área investigaram a formação de professores de outra área e não de Química, como no exemplo, "apresentar uma experiência em educação a distância de uma disciplina de Química geral para o curso de licenciatura em Física na Universidade Federal de Santa Catarina” (UFSC) (p.37) (2014QNESC14).

Com essa subcategoria, é possível perceber uma característica a respeito dos artigos publicados na revista QNESC, que apesar de esse ser um periódico específico da área de Ensino de Química, existem artigos publicados que abordaram o tema formação de professores de uma área diferente da Química. É importante ressaltar que essa categoria, sendo emergente, apresentou um número significativo de artigos, considerando o total de artigos investigados. Com esses resultados é possível caracterizar que predominaram artigos que abordaram outras temáticas como objetivo principal de pesquisa e apresentaram uma relação dessas com a formação de professores de Química.

\section{Considerações Finais}

A realização dessa pesquisa permitiu identificar o que tem sido publicado a respeito do tema formação de professores de Química na QNESC, no período de 1995-2020. Foi possível visualizar que uma quantidade significativa (25,59\%) dos artigos publicados nesse período abordou esse tema. A formação de professores de Química esteve presente como foco de pesquisa de artigos da QNESC, durante todo o período investigado. No entanto, houve um aumento expressivo no interesse pelo tema nos últimos doze anos do levantamento realizado.

A classificação dos artigos analisados em categorias permitiu algumas respostas para o questionamento que deflagrou a realização desta pesquisa: O que pesquisadores da área têm publicado acerca do tema formação de professores de Química no periódico QNESC?

Foi possível evidenciar que o tema formação de professores de Química tem como foco de investigação os conteúdos: Formação inicial, Formação continuada, Profissionalização docente e Prática pedagógica, por conseguinte, nossas categorias assumidas a priori. Sendo assim, compreende-se que esses assuntos caracterizam esse tema. Além disso, concluiu-se que houve uma concentração maior de artigos que abordaram a Formação inicial. De forma equivalente encontrou-se pesquisas a respeito da Profissionalização docente e da Prática pedagógica. No entanto, notou-se uma carência de artigos com foco em Formação continuada, com isso aponta-se para a necessidade de investigações a respeito do assunto.

Também foi possível identificar duas categorias emergentes assim denominadas: Artigos que mesclam categorias, que 
são investigações híbridas, que abordaram dois ou mais desses assuntos em um único artigo; e a categoria Outras temáticas e a formação de professores, que não se enquadraram nas categorias anteriores.

Em síntese, foi possível evidenciar características importantes a respeito da formação de professores de Química, tais como entender o desenvolvimento de pesquisas acerca da formação de professores de Química ao longo do tempo, no período investigado (1995-2020) e também os principais assuntos que permeiam a temática. Os resultados apontam os conteúdos mais desenvolvidos em pesquisa, o que possibilita aos pesquisadores uma visão de quais temas ainda necessitam de maior aprofundamento. No entanto, tem-se o conhecimento de que outras informações são relevantes e podem complementar essa caracterização, como instituições e região geográfica dos autores dos artigos, , a relação das publicações com a sessão temática na qual se encontram na QNESC, dentre outras questões, que são deixadas em aberto para o desenvolvimento de futuras pesquisas.

\section{Agradecimentos}

Agradecemos ao Conselho Nacional de Desenvolvimento Científico e Tecnológico (CNPq) e à Coordenação de Aperfeiçoamento de Pessoal de Nível Superior (CAPES) pelo apoio financeiro.

\section{Referências}

André, M. E. D. A. (2009). A produção acadêmica sobre formação de professores: um estudo comparativo das dissertações e teses defendidas nos anos 1990 e 2000. Brasileira de pesquisa sobre formação docente, 1(1), 41-56.

Beltran, N. O. (1995). [Editorial]. Química Nova na Escola, (1).

Conselho Nacional de Educação. (2015, julho 2). Resolução CNE n 2/2015 define as Diretrizes Curriculares Nacionais para a formação inicial em nível superior (cursos de licenciatura, cursos de formação pedagógica para graduados e cursos de segunda licenciatura) e para a formação continuada. Diário Oficial da União, Brasília. Seção 1, 8-12. http://pronacampo.mec.gov.br/images/pdf/res_cne_cp_02_03072015.pdf

Dassoler, O. B., \& Lima, D. M. S. (2012). A formação e a profissionalização docente: características, ousadia e saberes. Anais do Seminário de Pesquisa em Educação da Região Sul, Anped Sul, Caxias do Sul, RS, Brasil, 9. http://www.ucs.br/etc/conferencias/index.php/anpedsul/9anpedsul/paper/viewFile/3171/522

Coordenação de Aperfeiçoamento de Pessoal de Nível Superior - CAPES. (2013). Diretoria de formação de professores da educação básica - DEB: relatório de gestão PIBID. Recuperado de http://www.capes.gov.br/images/stories/download/bolsas/1892014-relatorioPIBID.pdf

Galiazzi, M. C., \& Moraes, R. (2002). Educação pela pesquisa como modo, tempo e espaço de qualificação da formação de professores de Ciências. Ciência \& Educação, 8(2), 237-252.

Gatti, B. A. (2016). Formação de professores: condições e problemas atuais. Internacional de Formação de Professores, 1(2), 161-171.

Gil-Pérez, D., \& Carvalho, A. M. P. (2003). Formação de professores de Ciências: tendências e inovações. (7a ed.). São Paulo: Cortez.

Kasseboehmer, A. C., \& Ferreira, L. H. (2008). O espaço da Prática de Ensino e do Estágio Curricular nos cursos de formação de professores de Química das IES públicas paulistas. Química Nova, 31(3), 694-699.

Lôbo, S. F., \& Moradillo, E. F. (2003). Epistemologia e a formação docente em química. Química Nova na Escola, $17,39-41$.

Maldaner, O. A. (1999). A pesquisa como perspectiva de formação continuada do professor de química. Química Nova, 22(2), $289-292$.

Maldaner, O. A. (2013). A Formação inicial e continuada de professores de química: Professores/Pesquisadores. (4a ed.). Ijuí: Unijuí.

Ministério da Educação. (2017). Cadastro Nacional de Cursos e Instituições de Educação Superior: Cadastro e-MEC. https://emec.mec.gov.br/

Moraes, R., \& Galiazzi, M. do C. (2011). Análise Textual Discursiva. (4a ed). Ijuí: Unijuí.

Mortimer, E. F., Quadros, A. L., Silva, A. S. F., Oliveira, L. A., \& Freitas, J. C. (2015). A Pesquisa em Ensino de Química na QNESC: uma análise de 2005 a 2014. Química Nova na Escola, 37(especial2), 188-192.

Nascimento, F., Fernandes, H. L., \& Mendonça, V. M. (2010). O Ensino de Ciências no Brasil: história, formação de professores e desafios atuais. HISTEDBR, 10(39), 225-249.

Nóvoa, A. (1992). Formação de professores e profissão docente. In A. Nóvoa, Os professores e a sua formação (pp. 13-33). Lisboa: Dom Quixote.

Paraná. (2016). Secretaria de Estado da Educação - Suritiba. http://www.gestaoescolar.diaadia.pr.gov.br/arquivos/File/pde_roteiros/2016/documento_sintese_pde_2016.pdf 
Passos, A. M. (2009). Um estudo sobre a formação de professores de Ciências e Matemática. (Dissertação de Mestrado). Universidade Estadual de Londrina, Londrina, PR, Brasil.

Passos, M. M. (2009). O professor de matemática e sua formação: análise de três décadas da produção bibliográfica em periódicos na área de Educação Matemática no Brasil. (Tese de doutorado). Universidade Estadual Paulista, Faculdade de Ciências, Bauru, SP, Brasil.

Queiroz, S. L., \& Veras, L. (2015). Química Nova na Escola: contribuições para o desenvolvimento de atividades didáticas. Química Nova na Escola, 37(especial), 133-139.

Santos, V. A. A. dos, Sousa, R. S. de, \& Derossi, I. N. (2020). A potencialidade do teatro do oprimido na formação de professores de Química. Research, Society and Development, 9(8), 1-23.

Schnetzler, R. P. (2002). A pesquisa em Ensino de Química no Brasil: Conquista e Perspectivas. Química Nova, 25(1), 14-24.

Selles, S. E. (2002). Formação continuada e desenvolvimento profissional de professores de Ciências: anotações de um projeto. Ensaio - Pesquisa em Educação em Ciências, 2(2), 167-181.

Silva, F. A. R., Alves, J. V., Junior, Travassos, L. C. P., \& Carmo, P. T. E. S. (2008). A importância das novas tecnologias no processo ensino-aprendizagem. Tecer, $1(1), 13-19$.

Silva, G. S., \& Santos, D. O. (2015). Formação de Professores em publicações da Revista Química Nova na Escola na última década. Scientia Plena, 11, 1-10.

Silva, J. M. N. da, \& Nunes, V. G. C. (2020). Formação continuada docente: uma análise a partir da Lei de Diretrizes e Bases da Educação Nacional (LDB/1996) e das Diretrizes Curriculares Nacionais para a Formação Inicial e Continuada de Professores da Educação Básica (Resolução CNE-CP 2/2015). Research, Society and Development, 9(8), 1-22.

Silva, O. B., \& Queiroz, S. L. (2016). Mapeamento da pesquisa no campo da formação de professores de Química no Brasil. Investigações em Ensino de Ciências, 2l(1), 62-93.

Silva, O. B., \& Queiroz, S. L. (2017). Produção Acadêmica sobre a Formação de Professores de Química no Brasil: Focos Temáticos das Dissertações e Teses Defendidas no Período de 2001 a 2010. Alexandria, 10(1), 271-304.

Silva, V. F., \& Bastos, F. (2012). Formação de professores de Ciências: reflexões sobre a formação continuada. Alexandria, 5(2), 150-188.

Zimmermann, E., \& Bertani, J. A. (2003). Um novo olhar sobre os cursos de formação de professores. Caderno Brasileiro de Ensino de Física, 20 (1), $43-62$.

\section{ANEXO}

Relação dos títulos dos artigos selecionados em ordem cronológica, com o volume e número (quando presente), páginas inicial e final e o código.

1. Importância, sentido e contribuições de pesquisas para o Ensino de Química. v.1, p.27-31. (1995QNESC1)

2. Concepções sobre o papel da linguagem no processo de elaboração em Química. v.2, p.27-30. (1995QNESC2)

3. Formação continuada de professores de Química. v.4, p.12-17. (1996QNESC1)

4. Função social: o que significa Ensino de Química para formar o cidadão. v.4, p.28-34. (1996QNESC2)

5. Imagens de Ciências em manuais de Química portugueses. v.6, p.23-29. (1997QNESC1)

6. Estudando os plásticos: tratamento de problemas autênticos no Ensino de Química. v.5, p.6-10. (1997QNESC2)

7. Reflexões sobre o currículo a partir da leitura de um livro para crianças. v.9, p.23-27. (1999QNESC1)

8. Estratégias e táticas de resistência nos primeiros dias de aula de Química. v.10, p.38-42. (1999QNESC2)

9. As aulas de Química como espaço de investigação e reflexão. v.9, p.14-17. (1999QNESC3)

10. Hipermídia no ensino de modelos atômicos. v.10, p.17-20. (1999QNESC4)

11. Fotossíntese: um tema para o Ensino de Ciências? v.12, p.24-29. (2000QNESC1)

12. Possibilidades de investigação-ação em um programa de formação continuada de professores de Química. v.14, p.36-39. (2001QNESC1)

13. Mediação interdisciplinar na construção de um projeto de Ensino de Química: uma análise pautada no diálogo de diferentes saberes. v.16, p.36-40. (2002QNESC1)

14. Concepções e alertas sobre formação continuada de professores de Química. v.16, p.15-20. (2002QNESC2)

15. Mudanças na prática de Ensino de Química pela formação dos professores em História e Filosofia das Ciências. v.18, p.31-36. (2003QNESC1)

16. Epistemologia e a formação docente em Química. v.17, p. 39-41. (2003QNESC2).

17. Corantes naturais: extração e emprego como indicadores de pH. v.17, p.27-31. (2003QNESC3)

18. A pesquisa no Ensino de Química e a importância da Química Nova na Escola. v.20, p.49-54. (2004QNESC1)

19. Dez anos de Química Nova na Escola: a consolidação de um projeto da Divisão de Ensino da SBQ. v.20, p.3-10. (2004QNESC2)

20. A pesquisa na formação inicial de professores de Química: abordando o tema drogas no Ensino Médio. v.24, p.25-29. (2006QNESC1)

21. Formação inicial em serviço de professores de Química na Bahia: história de uma vida. v.26, p.13-16. (2007QNESC1)

22. A chuva ácida na perspectiva de tema social: um estudo com professores de Química. v.25, p.14-19. (2007QNESC2)

23. Formação de professores de Química: concepções e proposições. v.27, p.26-29. (2008QNESC1)

24. Ressignificando a formação de professores de Química para a Educação Especial e Inclusiva: uma história de parcerias. v.30, p.27-33. (2008QNESC2)

25. O conhecimento químico e a questão ambiental na formação docente. v.29, p.30-33. (2008QNESC3)

26. Currículo e formação profissional: cenas do cotidiano de um instituto de pesquisa. v.30, p.49-54. (2008QNESC4)

27. O diário de aula coletivo no estágio da licenciatura em Química: dilemas e seus enfrentamentos. v.30, p.42-48. (2008QNESC5)

28. Ensinar Ciências por investigação: um desafio para os formadores. v.29, p.24-29. (2008QNESC6)

29. Formação contínua de professores para uma orientação CTS do Ensino de Química: um estudo de caso. v.27, p.30-33. (2008QNESC7)

30. Consensos sobre a Natureza da Ciência: a Ciência e a tecnologia na sociedade. v.27, p.34-50. (2008QNESC8)

31. Experimentando Química com segurança. v.27, p.57-60. (2008QNESC9)

32. A formação de professores de Química no Estado de Rondônia: necessidades e apontamentos. v.31, n.2, p.113-122. (2009QNESC1)

33. Formação de professores de Química na Universidade de Brasília: construção de uma proposta de inovação curricular. v.31, n.2, p.140-149. (2009QNESC2)

34. Ações interativo-reflexivas na formação continuada de professores: o projeto folhas. v.31, n.2, p.96-103. (2009QNESC3) 
35. Relações entre concepções epistemológicas e perfil profissional presentes em projetos pedagógicos de cursos de licenciatura em Química do estado de Goiás. v.31, n.2, p.123-131. (2009QNESC4)

36. Grupos de estudos entre estudantes ingressantes (calouros) e veteranos: uma perspectiva alternativa de estudo e discussão na universidade. v.31, n.2, p.132-139. (2009QNESC5)

37. Por um outro percurso da construção do saber em Educação Química. v.31, n.1, p.18-22. (2009QNESC6)

38. A leitura dos estudantes do curso de licenciatura em Química: analisando o caso do curso a distância. v.31, n.4, p.235-240. (2009QNESC7)

39. A história da síntese de elementos transurânicos e extensão da tabela periódica numa perspectiva fleckiana. v.31, n.4, p.246-250. (2009QNESC8)

40. Maresia: uma proposta para o ensino de eletroquímica. v.31, n.3, p.190-197. (2009QNESC9)

41. A pesquisa na formação de formadores de professores: em foco, a Educação Química. v.32, n.4, p.257-266. (2010QNESC1)

42. O portal eletrônico interativo: contexto, estrutura, possibilidades de navegação e discursos sobre formação de professores de Química. v.32, n.4, p.249256. (2010QNESC2)

43. Narrativas acerca da Prática de Ensino de Química: um diálogo na formação inicial de professores. v.32, n.2, p.120-127. (2010QNESC3)

44. O Ensino das Ciências e a ética na escola: interfaces possíveis. v.32, n.4, p.227-232. (2010QNESC4)

45. As questões ambientais e a Química dos sabões e detergentes. v.32, n.3, p.169-175. (2010QNESC5)

46. A Química disciplinar em Ciências do $9^{\circ}$ ano. v.32, n.1, p.43-52. (2010QNESC6)

47. Leitura em sala de aula: um caso envolvendo o funcionamento da Ciência. v.32, n.3, p.191-199. (2010QNESC7)

48. O debate como estratégia em aulas de Química. v.32, n.1, p.26-30. (2010QNESC8)

49. Poesia de António Gedeão e a formação de professores de Química. v.33, n.2, p.77-84. (2011QNESC1)

50. Marcas do currículo na formação do licenciando: uma análise a partir dos temas de trabalhos finais de curso da licenciatura em Química da UFRJ (1998-2008). v.33, n.1, p.10-18. (2011QNESC2)

51. O livro didático de Química nas concepç̃es de professores do Ensino Médio da região Sul da Bahia. v.33, n.2, p.115-124. (2011QNESC3)

52. Terminologias químicas em libras: a utilização de sinais na aprendizagem de alunos surdos. v.33, n.1, p.37-46. (2011QNESC4)

53. A Matriz de referência do ENEM 2009 e o desafio de recriar o currículo de Química na Educação Básica. v.33, n.3, p.153-159. (2011QNESC5)

54. Práticas de processamento de alimentos: alternativas para o Ensino de Química em escola do campo. v.33, n.4, p.223-229. (2011QNESC6)

55. A Bioquímica do Candomblé - possibilidades didáticas de aplicação da lei federal 10639/03. v.33, n.2, p.85-92. (2011QNESC7)

56. Por que foi mesmo que a gente foi lá?: uma investigação sobre os objetivos dos professores ao visitar o Parque da Ciência Newton Freire-Maia. v.33, n.3, p.142-152. (2011QNESC8)

57. Proposta de formação de professores de Química por meio de uma licenciatura parcelada: possibilidade de melhoria da prática pedagógica versus formação aligeirada. v.34, n.3, p.136-146. (2012QNESC1)

58. O saber experiencial na formação inicial de professores a partir de atividades de iniciação à docência no subprojeto de Química do PIBID da Unesp de Araraquara. v.34, n.4, p.184-188. (2012QNESC2)

59. As contribuições do PIBID ao processo de formação inicial de professores de Química. v.34, n.4, p.210-219. (2012QNESC3)

60. Compreensões e significados sobre o PIBID para a melhoria da formação de professores de Biologia, Física e Química. v.34, n.4, p.266-277. (2012QNESC4)

61. Avaliando contribuições para a formação docente: uma análise de atividades realizadas no PIBID-Química da UFRPE. v.34, n.4, p.229-239. (2012QNESC5)

62. A influência do PIBID na formação dos acadêmicos de Química licenciatura da UFSM. v.34, n.4, p.167-172. (2012QNESC6)

63. O projeto água em foco como uma proposta de formação no PIBID. v.34, n.4, p.240-247. (2012QNESC7)

64. Histórias de sala de aula de professoras de Química: partilha de saberes e experiências nas rodas de formação do PIBID/FURG. v.34, n.4, p.256-265. (2012QNESC8)

65. Aumentando o interesse do alunado pela Química escolar e implantação da nova proposta curricular mineira: desenvolvimento e resultados de projeto seminal realizado no PIBID-UFSJ. v.34, n.4, p.173-183. (2012QNESC9)

66. Estudo de caso em aulas de Química: percepção dos estudantes de Nível Médio sobre o desenvolvimento de suas habilidades. v.34, n.4, p.220-228. (2012QNESC10)

67. A perspectiva de futuro profissional de licenciados em Química e o perfil de egresso desejado pela Universidade Estadual de Ponta Grossa - Paraná. v.34, n.3, p.147-154. (2012QNESC11)

68. Relatos de Experiências do Programa Institucional de Bolsa de Iniciação à Docência no Curso de Licenciatura em Química da Universidade Estadual do Norte Fluminense. v.34, n.4, p.201-209. (2012QNESC12)

69. O contexto amazônico na produção acadêmica de licenciandos em Química da Universidade Federal do Acre: revelações de um percurso formativo. v.34, n.2, p.67-74. (2012QNESC13)

70. 17 anos de Química Nova na Escola: notas de alguém que a leu como estudante no Ensino Médio e no Ensino Superior com aspirações à docência. v.34, n.1, p.16-20. (2012QNESC14)

71. Reflexões sobre modelos e representações na formação de professores com foco na compreensão conceitual da catálise enzimática. v.34, n.1, p.26-34 (2012QNESC15)

72. A utilização de vídeos didáticos nas aulas de Química do Ensino Médio para abordagem histórica e contextualizada do tema vidros. v.34, n.4, p.189200. (2012QNESC16)

73. Jogos no Ensino de Química: considerações teóricas para sua utilização em sala de aula. v.34, n.2, p.92-98. (2012QNESC17)

74. Nanotecnologia, um tema para o Ensino Médio utilizando a abordagem CTSA. v.34, n.1, p.3-9. (2012QNESC18)

75. Os saberes docentes na formação de professores de Química participantes do PIBID. v.35, n.4, p.272-282. (2013QNESC1)

76. A educação inclusiva na formação de professores e no Ensino de Química: a deficiência visual em debate. v.35, n.4, p.264-271. (2013QNESC2)

77. Ações e reflexões durante o Estágio Supervisionado em Química: algumas notas autobiográficas. v.35, n.4, p.283-291. (2013QNESC3)

78. A percepção dos licencia(n)dos em Química sobre o impacto do PIBID em sua formação para a docência. v.35, n.3, p.189-198. (2013QNESC4)

79. O PIBID e a licenciatura em Química num contexto institucional de pesquisa Química destacada: cenário, dificuldades e perspectivas. (2013QNESC5)

80. Dificuldades de ensino e aprendizagem dos modelos atômicos em Química. v.35, n.2, p.112-122. (2013QNESC6)

81. A análise do conhecimento pedagógico do conteúdo no planejamento de atividades com a utilização de modelos no Ensino de Química. v.35, n.2, p.123-131. (2013QNESC7)

82. A inovação na área de Educação Química. v.35, n.1, p.48-56. (2013QNESC8)

83. Visualizações no Ensino de Química: concepções de professores em formação inicial. v.35, n.3, p.199-208. (2013QNESC9)

84. Avaliação dos estudantes sobre o uso de imagens como recurso auxiliar no ensino dos conceitos químicos. v.35, n.1, p.19-26. (2013QNESC10)

85. Elaboração de hipóteses em atividades investigativas em aulas teóricas de Química por estudantes de Ensino Médio. v.35, n.3, p.158-165. (2013QNESC11)

86. Cotidiano e contextualização no Ensino de Química. v.35, n.2, p.84-91. (2013QNESC12)

87. Blogs na formação inicial de professores de Química. v.36, n.1, p.4-10. (2014QNESC1)

88. As contribuições do PIBID no processo de formação inicial de professores de Química: a experimentação como ferramenta na aprendizagem dos alunos do Ensino Médio. v.36, n.4, p.297-304. (2014QNESC2)

89. Experimentação e literatura: contribuições para a formação de professores de Química. v.36, n.2, p.93-100 (2014QNESC3) 
90. O diário virtual coletivo: um recurso para investigação dos saberes docentes mobilizados na formação de professores de Química de deficientes visuais. v.36, n.1, p.61-70. (2014QNESC4)

91. Construção da identidade docente na licenciatura em Química de um Instituto Federal de Educação Profissional. v.36, n.4, p.305-313. (2014QNESC5)

92. A aula experimental registrada em portfólios coletivos: a formação potencializada pela integração entre licenciandos e professores da Escola Básica. v.36, n.2, p.144-149. (2014QNESC6)

93. Narrativas centradas na contribuição do PIBID para a formação inicial e continuada de professores de Química. v.36, n.1, p.44-50. (2014QNESC7)

94. PIBID/Licenciatura em Química da Universidade de Brasília: inter-relacionando ensino, pesquisa e extensão. v.36, n.1, p.18-27. (2014QNESC8)

95. Situação de estudo em curso técnico: buscando alternativas para a iniciação à docência na interação interinstitucional. v.36, n.1, p.51-60. (2014QNESC9)

96. Reflexões do PIBID-Química da UFRN: para além da iniciação à docência. v.36, n.2, p.101-107. (2014QNESC10)

97. Condicionantes sobre o trabalho docente: a utilização de atividades experimentais em uma rede escolar pública municipal. v.36, n.3, p.176-184. (2014QNESC11)

98. Contribuições ao currículo da licenciatura a partir de histórias de sala de aula: o PIBID de Química da FURG. v.36, n.2, p. 135-143. (2014QNESC12)

99. Atividades didático-pedagógicas para o Ensino de Química desenvolvidas pelo projeto PIBID-IFG. v.36, n.3, p.211-219. (2014QNESC13)

100. Relato sobre docência compartilhada em educação a distância. v.36, n.1, p.37-43. (2014QNESC14)

101. Abordagem ambiental em livros didáticos de Química: princípios da carta de Belgrado. v.36, n.3, p.220-230. (2014QNESC15)

102. Dez anos da lei de libras: um conspecto dos estudos publicados nos últimos 10 anos nos anais das reuniões da Sociedade Brasileira de Química. v.36, n.3, p.185-193. (2014QNESC16)

103. Oficina temática Composição Química dos alimentos: uma possibilidade para o Ensino de Química. v.36, n.4, p.289-296. (2014QNESC17)

104. A prática da escrita e reescrita em aulas de Química como potencializadora do aprender Química. v.36, n.4, p.314-320. (2014QNESC18)

105. A água da fonte natural: sequência de atividades envolvendo os conceitos de substância e mistura. v.36, n.2, p.108-118. (2014QNESC19)

106. A proposta metodológica de ilha interdisciplinar de racionalidade em um curso de licenciatura em Química: discutindo informações de corrente de email. v.36, n.2, p.126-134. (2014QNESC20)

107. Química e educação ambiental: uma experiência no Ensino Superior. v.36, n.2, p.119-125. (2014QNESC21)

108. Oficinas pedagógicas: uma proposta para a reflexão e a formação de professores. v.37, n.2, p.125-133. (2015QNESC1)

109. Aprendizagem baseada em casos investigativos e a formação de professores: o potencial de uma aula prática de volumetria para promover o ensino interdisciplinar. v.37, n. 2, p.112-119. (2015QNESC2)

110. Perspectiva de estudantes de Química sobre uma proposta de produção e aplicação de unidades didáticas e o impacto do PIBID na formação docente. v. 37, n.3, p.187-196. (2015QNESC3)

111. Perfil dos alunos de licenciaturas em Química que atuam no Programa Institucional de Bolsa de Iniciação à Docência e as influências para sua formação inicial. v.37, n.4, p.305-311. (2015QNESC4)

112. Zonas do perfil conceitual de calor que emergem na fala de professores de Química. v.37, n.especial1, p.55-67. (2015QNESC5)

113. Reflexões sobre a formação e a prática pedagógica do docente de Química cego. v.37, n.especial1, p.19-25. (2015QNESC6)

114. QNEsc e cadernos de pesquisa: uma nova perspectiva na formação do professor investigador. v.37, n.especial2, p.203-206. (2015QNESC7)

115. Química Nova na Escola: um caso de sucesso. v.37, n.especial2, p.121-126. (2015QNESC8)

116. 20 anos de QNEsc: uma história, muitas histórias. v.37, n.especial2, p.166-171. (2015QNESC9)

117. O aluno em foco nos 20 anos de Química Nova na Escola. v.37, n.especial2, p.193-197. (2015QNESC10)

118. A construção de significados em Química: a interpretação de experimentos por meio do uso de discurso dialógico. v.37, n.3, p.204-213. (2015QNESC11)

119. Espaços de formação continuada de professores em escolas pequenas e isoladas: uma lacuna a ser preenchida. v.37, n.3, p.214-223. (2015QNESC12)

120. Repensando o PIBID-Química da UFJF por meio da compreensão do perfil dos alunos das escolas parceiras. v.37, n.3, p.224-231. (2015QNESC13)

121. Espaço aberto: interface do Ensino de Química com a Educação. v.37, n.especial2, p.140-146. (2015QNESC14)

122. Química Nova na Escola: contribuições para o desenvolvimento de atividades didáticas. v.37, n.especial2, p.133-139. (2015QNESC15)

123. A pesquisa em Ensino de Química na QNESC: uma análise de 2005-2014. v.37, n.especial2, p.188-192. (2015QNESC16)

124. Fazeres/Saberes em interação no cenário dos 20 anos da seção Relatos de Sala de Aula. v.37, n.especial2, p.178-187. (2015QNESC17)

125. Análise e reflexões sobre os artigos de Educação em Química e multimídia publicados entre 2005 e 2014. v.37, n.especial2, p.154-160. (2015QNESC18)

126. Conceitos científicos em destaque: enfoques da comunidade disciplinar de Ensino de Química na QNESC. v.37, n.especial2, p.161-166. (2015QNESC19)

127. A Química da cerveja. v.37, n.2, p.98-105. (2015QNESC20)

128. Estudo de ácidos e bases e o desenvolvimento de um experimento sobre a "força" dos ácidos. v.37, n.4, p.278-284. (2015QNESC21)

129. Relações entre gestos e operações epistêmicas mediadas pela representação estrutural em aulas de Química e suas implicações para a produção de significados. v.37, n.especial1, p.82-94. (2015QNESC22)

130. Tabela periódica interativa. v.37, n.3, p.180-186. (2015QNESC23)

131. A seção Química e Sociedade: Contribuições para um Ensino em diferentes contextos. v.37, n.especial2, p.146-153. (2015QNESC24)

132. Ensino-aprendizagem de Química na educação escolar indígena: o uso do livro didático de Química em um contexto Bakairi. v.37, n.4, p.249-256. (2015QNESC25)

133. Contribuição da escrita reflexiva à reelaboração de saberes: olhares de licenciandos participantes do PIBID Química. v.38, n.1, p.54-59. (2016QNESC1)

134. A experimentação na docência de formadores da área de Ensino de Química. v.38, n.1, p.84-98. (2016QNESC2)

135. Anotações a experimentação e literatura: contribuições para a formação de professores de Química. v.38, n.2, p.121-126. (2016QNESC3)

136. Análise de alimentos: contextualização e interdisciplinaridade em cursos de formação continuada. v.38, n.2, p.149-156. (2016QNESC4)

137. A influência do PIBID/Química da UFRGS sobre o desempenho escolar de alunos de Ensino Médio. v.38, n.2, p.157-166. (2016QNESC5)

138. Análise de instrumentos de avaliação como recurso formativo. v.38, n.1, p.33-39. (2016QNESC6)

139. Revisão no campo: o processo de ensino-aprendizagem dos conceitos ácido e base entre 1980 e 2014. v.38, n.2, p.185-196. (2016QNESC7)

140. Desenvolvimento e aplicação de webquest para Ensino de Química Orgânica: controle biorracional da lagarta-do-cartucho do milho. v.38, n.1, p.47-53. (2016QNESC8)

141. Ensino por temas: a qualidade do ar auxiliando na construção de significados em Química. v.38, n.1, p.40-46. (2016QNESC9)

142. Isômeros, funções orgânicas e radicais livres: análise da aprendizagem de alunos do Ensino Médio segundo a abordagem CTS. v.38, n.1, p.60-69. (2016QNESC10)

143. Concepções sobre substância: relações entre contextos de origem e possíveis atribuições de sentidos. v.38, n.1, p.70-78. (2016QNESC11)

144. Abordagem da Química no novo ENEM: uma análise acerca da interdisciplinaridade. v.38, n.2, p.112-120. (2016QNESC12)

145. Análise de uma estratégia de estudo de caso vivenciada por licenciandos de Química. v.38, n.2, p.173-180. (2016QNESC13)

146. Uso de softwares educacionais, objetos de aprendizagem e simulações no Ensino de Química. v.38, n.2, p.104-111. (2016QNESC14)

147. Os estágios e a formação inicial de professores: experiências e reflexões no curso de Licenciatura em Química da UEL. v.38, n.3, p.306-317. (2016QNESC15)

148. Caminhos e descaminhos da formação docente: uma análise dos projetos pedagógicos de cursos de Licenciatura em Química no Rio de Janeiro. v.39, n.3, p.261-267. (2017QNESC1) 
149. Práxis e Identidade Docente: Entrelaces no Contexto da Formação pela Pesquisa na Licenciatura em Química. v. 40, n. 1, p.44-54. (2018QNESC1)

150. A Filosofia na Formação de Professores de Química em Minas Gerais: O que se mostra nos componentes curriculares de licenciaturas em Química? v. 41, n. 4, p.399-413. (2019QNESC1)

151. O papel da prática como componente curricular na formação inicial de professores de Química: possibilidades de inovação didático-pedagógica. v.39, n.3, p.250-260. (2017QNESC2)

152. Tendências das Pesquisas de Gênero na Formação Docente em Ciências no Brasil. v. 41, n. 1, p.98-107. (2019QNESC2)

153. O jornal da Química como etapa inicial de abordagem problematizadora: proposta para ensino e formação de professores. v.41, n.2, p.139-147. (2019QNESC3)

154. Saberes docentes compartilhados durante o estágio supervisionado: uma experiência com licenciandos em Química. v.41, n.2, p.156-161. (2019QNESC4)

155. Os sistemas de atividade na interpretação da produção curricular por 'situação de estudo': fundamentos teórico-metodológicos. v.41, n.1, p.55-68. (2019QNESC5)

156. Ensino de Bioquímica e formação docente: propostas de projetos voltados para o Ensino Básico, desenvolvidos por estudantes de licenciatura. v.38, n.3, p.224-236. (2016QNESC16)

157. O professor formador em foco: identidade e concepções do fazer docente. v.39, n.4, p.356-367. (2017QNESC3)

158. Ensino de Química e codocência: interdependência docente/tradutor e intérprete de língua de sinais. v.41, n.2, p.162-170. (2019QNESC6)

159. A constituição do professor/pesquisador no componente curricular de monografia por meio da escrita em diários de pesquisa. v.39, n.2, p.170-178. (2017QNESC4)

160. O laboratório de Ciências e a realidade dos docentes das escolas estaduais de São Carlos - SP. v.38, n.3, p.208-214. (2016QNESC17)

161. O tema "alumínio" nas coleções do PNLD 2018: uma análise de acordo com a educação CTS. v.41, n.3, p.233-241. (2019QNESC7)

162. Interfaces disciplinares no Ensino de Ciências: uma perspectiva docente. v.41, n.2, p.200-209. (2019QNESC9)

163. Da intencionalidade à responsabilidade lúdica: novos termos para uma reflexão sobre o uso de jogos no Ensino de Química. v.xx, n.yy, p. xxx. (2018QNESC2)

164. Educação ambiental no Ensino de Química: reciclagem de caixas Tetra Pak® na construção de uma tabela periódica interativa. v.39, n.3, p.268-276. (2017QNESC15)

165. Compreensões sobre a cegueira e as atividades experimentais no ensino de Química: quais as relações possíveis? v.41, n.2, p.190-199. (2019QNESC10)

166. O ensino de Química no ensino CTS brasileiro: uma revisão bibliográfica de publicações em periódicos. v.xx, n.yy, p.xxx. (2018QNESC6)

167. Letramento gráfico: perspectivas presentes nos PCNEM e ações no ensino de Química. v.41, n.3, p.300-313. (2019QNESC8)

168. A utilização de uma oficina de ensino no processo formativo de alunos de Ensino Médio e de licenciandos. v.39, n.1, p.27-34. (2017QNESC5)

169. Elaboração de textos de divulgação científica e sua avaliação por alunos de licenciatura em Química. v.38, n.4, p.387-403. (2016QNESC18)

170. Ser ou não ser professor: duas faces de uma graduação em Química. v. 41, n.4, p.377-385. (2019QNESC11)

171. Um outro olhar sobre as ligações hidrogênio. v.41, n.1, p.10-16. (2019QNESC12)

172. Sensibilidade moral de licenciandos em Química diante de conflito ético na prática científica. v.41, n.1, p.69-81. (2019QNESC13)

173. Tecnologia assistiva e ensino de Química: reflexões sobre o processo educativo de cegos e a formação docente. v.38, n.4, p.297-305. (2016QNESC19)

174. Análise das estratégias de ensino utilizadas para o ensino da tabela periódica. v.38, n.4, p.349-359 (2016QNESC20).

175. A polêmica da fosfoetanolamina no ensino de Química: articulações entre o planejamento de ensino e a comunicação científica. v.41, n.4, p.327-334. (2019QNESC14)

176. Proposta pedagógica para o ensino explícito de argumentação: o caso da controvérsia histórica do gás oxigênio. v.41, n.3, p.266-274. (2019QNESC15)

177. Recursos instrucionais inovadores para o ensino de Química. v.39, n.1, p.12-18. (2017QNESC8)

178. A vivência formativa de uma estudante do Ensino Médio no ambiente universitário: olhares para a Química e a pesquisa científica. v.41, n.3, p.286-299. (2019QNESC16)

179. Contribuições da Sociologia de Bourdieu para repensar a Educação e o ensino de Ciências. v.39, n.4, p.321-328. (2017QNESC14)

180. Tabela periódica: concepções de estudantes ao longo do Ensino Médio. v.41, n.4, p.386-393. (2019QNESC17)

181. Pistas orgânicas: um jogo para o processo de ensino e aprendizagem da Química. v.40, n.1, p. 25-32. (2018QNESC3)

182. Combustíveis: uma abordagem problematizadora para o Ensino de Química. v.39, n.1, p.68-74 (2017QNESC9).

183. Ensino de Química para deficientes visuais: a importância da experimentação num enfoque multissensorial. v.39, n.2, p.195-203. (2017QNESC10)

184. Monteiro Lobato e Paulo Freire: problematizando o poço do Visconde. v.39, n.1, p.89-103. (2017QNESC6)

185. Concepções sobre substância: relações entre contextos de origem e possíveis atribuições de sentidos. v.38, n.1, p.70-78. (2016QNESC21)

186. Tem dendê, tem axé, tem química: sobre história e cultura africana e afro-brasileira no ensino de Química. v.39, n.1, p.19-26. (2017QNESC13)

187. Motivação dos alunos: reflexões sobre o perfil motivacional e a percepção dos professores. v.39, n.1, p.75-82. (2017QNESC11)

188. Ensino de Química e a Ciência de Matriz Africana: uma discussão sobre as propriedades metálicas. v.39, n.2, p.131-141. (2017QNESC12)

189. As videoaulas em foco: que contribuições podem oferecer para a aprendizagem de ligações químicas de estudantes da Educação Básica? v.40, n.4, p.287-296. (2018QNESC4)

190. Corantes: uma abordagem com enfoque Ciência, Tecnologia e Sociedade (CTS) usando processos oxidativos avançados. v.40, n.4, p.249-257. (2018QNESC5)

191. A experimentação no ensino de Química para deficientes visuais com o uso de tecnologia assistiva: o termômetro vocalizado. v.39, n.3, p.245-249. (2017QNESC7)

192. A dinâmica do contrato didático no ensino de calorimetria por resolução de situações-problema: a simultaneidade de duas relações contratuais. v.41, n.1, p.33-40. (2019QNESC18)

193. Alternate Reality Game (ARG): breve histórico, definições e benefícios para o ensino e aprendizagem da Química. v.41, n.4, p.335-343. (2019QNESC19)

194. Leite em "mama” África e a Educação para as Relações Étnico-Raciais (ERER) no ensino de Química. v.42, n.1, p.4-12. (2020QNESC1)

195. Contribuições do PIBID para a formação inicial de licenciandos em Química: análise de Teses e Dissertações. v.42, n.1, p.56-67. (2020QNESC2)

196. Práticas docentes que podem contribuir para a inclusão de alunos com síndrome de Asperger: uma abordagem alternativa para o ensino de Química. v.42, n.1, p.68-76. (2020QNESC3)

197. Categorias analíticas para a caracterização de ideias prévias de professores sobre o planejamento de ensino: contribuições para a formação de professores de Química críticos e autônomos. v.42, n.1, p.88-104. (2020QNESC4)

198. Um jogo didático para revisão de conceitos químicos e normas de segurança em laboratórios de Química. v.42, n.1, p.37-44. (2020QNESC5)

199. Investigação criminal e química forense: espaço não formal de aprendizagem investigativa. v.42, n.2, p.129-135. (2020QNESC6)

200. Química Experimental e a Lei 10.639/2003: a inserção da história e cultura africana e afro-brasileira no ensino de Química. v.42, n.2, p.136-146. (2020QNESC7)

201. Propostas de ensino de Química focadas nas questões étnico-raciais: uma experiência na licenciatura e seus desdobramentos para o nível médio. v.42, n.3, p.208-215. (2020QNESC8)

202. Quente e frio: sobre a educação escolar quilombola e o ensino de Química. v.42, n.3, p.269-280. (2020QNESC9)

203. A comida como prática social: sobre africanidades no ensino de Química. v.42, n.3, p.281-294. (2020QNESC10)

204. O ensino de Ciências na Educação Infantil: relatos de sala de aula. v.42, n.4, p.359-367. (2020QNESC11)

205. A temática "agrotóxico" no ensino de Química em sala de aula: análise de textos publicados na literatura. v.42, n.4, p.373-381. (2020QNESC12) 